\title{
Oocyte activation and phospholipase C zeta (PLC)): diagnostic and therapeutic implications for assisted reproductive technology
}

Walaa M Ramadan ${ }^{\dagger}$, Junaid Kashir ${ }^{\dagger}$, Celine Jones and Kevin Coward ${ }^{*}$

\begin{abstract}
Infertility affects one in seven couples globally and has recently been classified as a disease by the World Health Organisation (WHO). While in-vitro fertilisation (IVF) offers effective treatment for many infertile couples, cases exhibiting severe male infertility (19-57\%) often remain difficult, if not impossible to treat. In such cases, intracytoplasmic sperm injection (ICSI), a technique in which a single sperm is microinjected into the oocyte, is implemented. However, 1-5\% of ICSI cycles still fail to fertilise, affecting over 1000 couples per year in the UK alone. Pregnancy and delivery rates for IVF and ICSI rarely exceed 30\% and 23\% respectively. It is therefore imperative that Assisted Reproductive Technology (ART) protocols are constantly modified by associated research programmes, in order to provide patients with the best chances of conception. Prior to fertilisation, mature oocytes are arrested in the metaphase stage of the second meiotic division (MII), which must be alleviated to allow the cell cycle, and subsequent embryogenesis, to proceed. Alleviation occurs through a series of concurrent events, collectively termed 'oocyte activation'. In mammals, oocytes are activated by a series of intracellular calcium $\left(\mathrm{Ca}^{2+}\right)$ oscillations following gamete fusion. Recent evidence implicates a sperm-specific phospholipase C, PLCzeta (PLC), introduced into the oocyte following membrane fusion as the factor responsible. This review summarises our current understanding of oocyte activation failure in human males, and describes recent advances in our knowledge linking certain cases of male infertility with defects in PLC expression and activity. Systematic literature searches were performed using PubMed and the ISI-Web of Knowledge. Databases compiled by the United Nations and World Health Organisation databases (UNWHO), and the Human Fertilization and Embryology Authority (HFEA) were also scrutinised. It is clear that PLC plays a fundamental role in the activation of mammalian oocytes, and that genetic, molecular, or biochemical perturbation of this key enzyme is strongly linked to human infertility where oocyte activation is deficient. Consequently, there is significant scope for our understanding of PLCZ to be translated to the ART clinic, both as a novel therapeutic agent with which to rescue oocyte activation deficiency (OAD), or as a prognostic/diagnostic biomarker of oocyte activation ability in target sperm samples.
\end{abstract}

Keywords: Oocyte activation, Phospholipase c zeta (PLCzeta), Sperm, Male infertility, Assisted reproductive technology (ART), Therapeutic, Diagnostic, Biomarker

\footnotetext{
*Correspondence: kevin.coward@obs-gyn.ox.ac.uk

${ }^{\dagger}$ Equal contributors

Nuffield Department of Obstetrics and Gynaecology, University of Oxford,

Level 3, Women's Centre, John Radcliffe Hospital, Headington, Oxford, OX3

9DU, UK
}

\section{Biomed Central}

(c) 2012 Ramadan et al.; licensee BioMed Central Ltd This is an Open Access article distributed under the terms of the Creative Commons Attribution License (http://creativecommons.org/licenses/by/2.0), which permits unrestricted use, distribution, and reproduction in any medium, provided the original work is properly cited. 


\section{Introduction}

Infertility affects one in seven couples globally [1-3], a worrying statistic which has led to the classification of infertility as a recognised disease by the World Health Organisation (WHO; [4]). In the UK, 1.5\% of all births are the result of assisted reproductive technology (ART) [5]. In some other developed countries, this figure can reach 7\% $[3,6]$. However, while conventional in-vitro fertilisation (IVF) provides effective treatment for many infertile couples, several conditions, including severe male infertility (accounting for $19-57 \%$ of cases), remain untreatable with a normal IVF cycle [7]. In such cases, intracytoplasmic sperm injection (ICSI), a more sophisticated technique in which an individual sperm is injected directly into the oocyte [8], is implemented and has been shown to be an effective approach for many cases. Despite this revolutionary approach, it is estimated that $1-5 \%$ of ICSI cycles still fail $[6,9]$. Considering that approximately $52 \%$ of all IVF cycles in the UK involve ICSI [5], this represents a significant problem, and on average would affect over 1000 couples per year in the UK alone. Indeed, despite the global expansion of ART, pregnancy and delivery rates following IVF and ICSI protocols rarely exceed $32 \%$ and 33\%, respectively [10]. Consequently, there is constant need for a greater understanding of the molecular and physiological mechanisms underlying infertility, such as ICSI failure and other idiopathic conditions, such that the ART protocols can be improved, refined, or replaced. It is the intention of this review to discuss how investigative research into the process of oocyte activation has led to significant potential to both enhance existing ART protocols and provide the possibility of novel diagnostic tests for certain types of male factor infertility.

\section{Oocyte activation}

IPrior to fertilisation, mature oocytes remain arrested in the metaphase stage of the second meiotic division (MII) [11]. Arrest is maintained by stabilisation of M-Phase promoting factor (MPF), the universal driver for G2/M cell cycle transition. MPF is a heterodimer consisting of a regulatory cyclin subunit, cyclin $B$, and a catalytic subunit, Cdc2 kinase. Active Cdc2 drives entry into M-phase by phosphorylating substrates leading to nuclear envelope breakdown and spindle formation [12]. Upon fusion with a sperm, MII arrest is alleviated, thereby allowing cell cycle progression, cell division, and embryogenesis to proceed. Release of meiotic arrest occurs via a series of concurrent events, collectively termed 'oocyte activation', which convert the oocyte into a totipotent zygote, able to form all types of body cells $[3,13]$. These morphological and biochemical events include cortical granule (CG) exocytosis to prevent polyspermy, extrusion of the second polar body, maternal RNA recruitment, male and female pro-nuclear
(PN) formation, and the initiation of embryonic gene expression [14-20].

Early research utilised calcium $\left(\mathrm{Ca}^{2+}\right)$ sensitive dyes to demonstrate that non-mammalian oocytes, such as those from sea urchins and frogs, were activated by a single cytosolic $\mathrm{Ca}^{2+}$ transient initiating from the point of sperm entry and traversing across the egg to the opposite pole. In contrast, mammalian oocytes exhibit a series of $\mathrm{Ca}^{2+}$ 'oscillations' (Figure 1) [12,14,15,21-23]. These changes in cytosolic $\mathrm{Ca}^{2+}$ are now thought to be the universal trigger for oocyte activation and development $[14,19,24]$. Indeed, microinjection of $\mathrm{Ca}^{2+}$ ions alone triggered embryo development to the blastocyst stage in mice $[23,25]$. However, the nature, amplitude, duration, and frequency of this vital signal are species- specific $[15-17,26]$.

In mammalian oocytes, $\mathrm{Ca}^{2+}$ oscillations are now generally accepted to be the direct result of inositol trisphosphate $\left(\mathrm{IP}_{3}\right)$-mediated $\mathrm{Ca}^{2+}$ release from intracellular $\mathrm{Ca}^{2+}$ stores Isuch as the endoplasmic reticulum (ER) [23,27-38]. Blocking, down-regulating, or reducing the expression levels of $\mathrm{IP}_{3}$ receptors $\left(\mathrm{IP}_{3} \mathrm{Rs}\right)$ in mouse and hamster oocytes, all inhibit $\mathrm{Ca}^{2+}$ oscillations and thus oocyte activation [39-42]. Furthermore, cytosolic increases in $\mathrm{IP}_{3}$ concentration during fertilisation in mammalian oocytes [23] provided further support for the importance of $\mathrm{IP}_{3}$ levels and $\mathrm{IP}_{3}$-mediated $\mathrm{Ca}^{2+}$ release.

Oocytes are remarkably sensitive to the specific frequency and amplitude of the $\mathrm{Ca}^{2+}$ oscillations evoked. The initial increase in intracellular $\mathrm{Ca}^{2+}$ appears to be critical for the initiation of both early and late events of oocyte activation $[14,17,43]$, as well as exerting peri-implantation effects upon gene expression and development to term [17,44-46]. Many early activation events of physiological importance are not simultaneously initiated following the initial $\mathrm{Ca}^{2+}$ transient, but occur in a temporal order $[17,45]$ through spatial and temporal regulation of periodic $\mathrm{Ca}^{2+}$ release [47]. The frequency and amplitude of $\mathrm{Ca}^{2+}$ oscillations influence cell cycle progression rates and protein expression profiles in early mouse embryos [16], and embryonic development in rabbits $[19,48]$. Considering that the rate of progression to the 2- and 4-cell stages of human oocytes following fertilisation has been proposed as an indicator of normal embryogenesis [49], the profile of $\mathrm{Ca}^{2+}$ oscillations at fertilisation may not only be necessary for oocyte activation, but may also be equally important for subsequent embryogenesis. Indeed, alterations in the $\mathrm{Ca}^{2+}$ oscillatory activity of vitrified mouse oocytes were found to directly affect oocyte quality and subsequent embryonic development [50].

Many theories have attempted to explain how the fertilising sperm elicits $\mathrm{Ca}^{2+}$ oscillations following mammalian gamete fusion [24,32,33,35,51]. One such model relates the interaction of the sperm with a coupled receptor on the plasma membrane of the oocyte, which in turn 


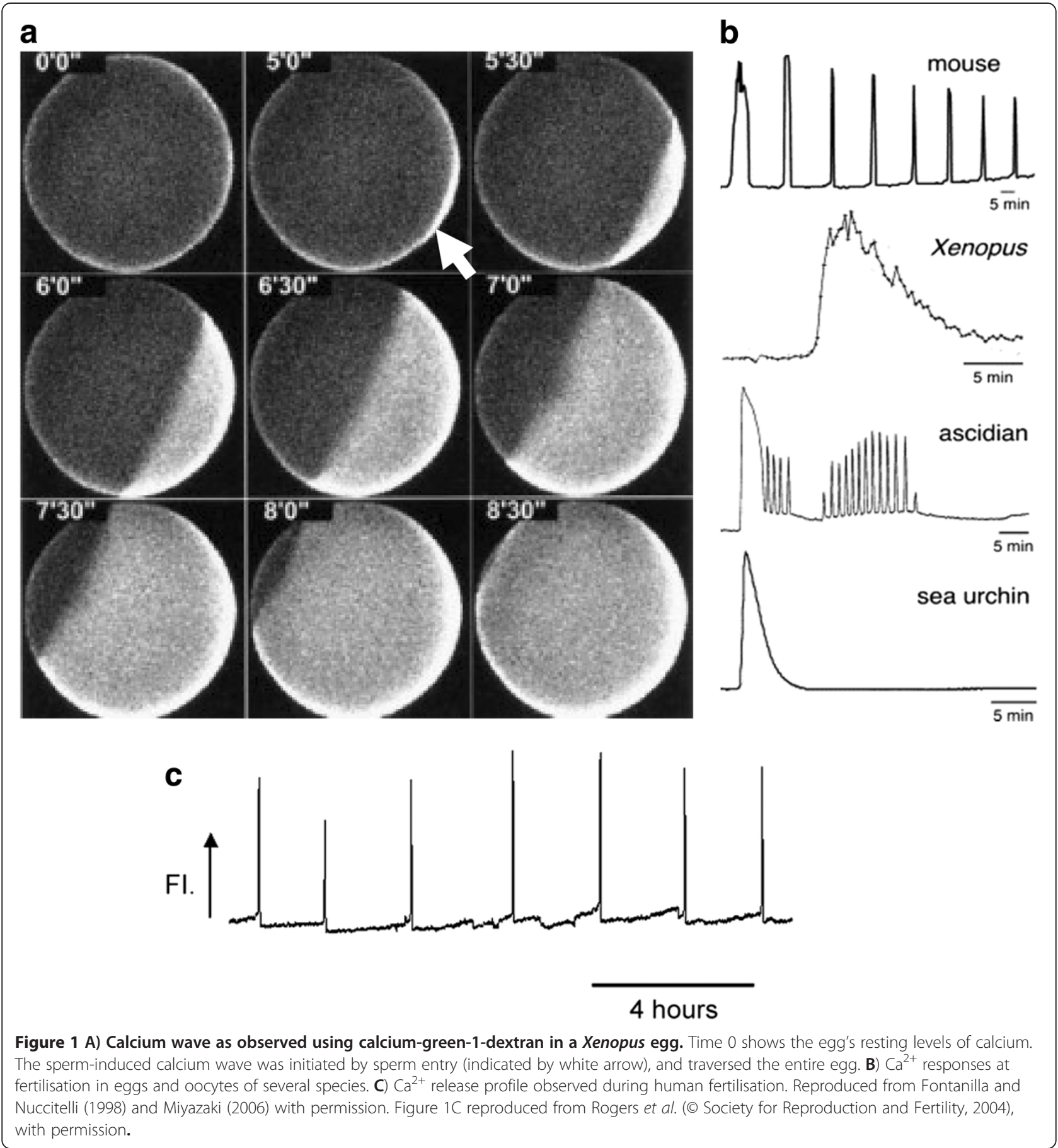

stimulates the release of $\mathrm{Ca}^{2+}$ either through a G-protein linked cascade or via tyrosine kinase activity. Indeed, this 'membrane/receptor' model was the dominant theory for many years $[35,52]$. However, despite many targeted studies, a sperm ligand/oocyte receptor of this nature still remains to be characterised [35]. Critically, the successful nature of microinjection techniques such as ICSI casts significant doubt over the membrane receptor theory as this technique bypasses sperm/oocyte membrane interaction completely.

A second model proposed that a soluble oocyte activation factor is released into the oocyte following gamete fusion, and subsequently interacts with ooplasmic components, ultimately leading to $\mathrm{Ca}^{2+}$ release. Indeed, the injection of sperm extracts into the oocytes of a variety of species, including marine worms, and ascidians, 
resulted in successful $\mathrm{Ca}^{2+}$ release and oocyte activation $[15,53,54]$. Sperm extracts from frogs, chickens, and tilapia fish, also trigger $\mathrm{Ca}^{2+}$ oscillations in mouse oocytes [55-57], suggesting the existence of a similar sperm-based mechanism throughout a wide spectra of species. A considerable body of research suggested that the $\mathrm{IP}_{3}$-dependant nature of oocyte activation depended upon a phospholipase C (PLC)-mediated mechanism [35], suggesting that the oocyte activation factor was a sperm-based PLC $[26,48,58]$. This supported the notion that the soluble sperm factor was a PLC which mediated the hydrolysis of phosphotidylinositol 4,5-bisphosphate $\left(\mathrm{PIP}_{2}\right)$ to $\mathrm{IP}_{3}$ and diacylglycerol (DAG), leading to the activation of signalling pathways mediated by protein kinases, such as protein kinase $\mathrm{C}$ (PKC) $[23,39,59]$. General consensus agreed that the soluble factor responsible for $\mathrm{Ca}^{2+}$ release within oocytes was sperm-specific, as extracts from other tissues did not result in $\mathrm{Ca}^{2+}$ induction upon oocyte injection [53,60]. However, the specific identity of such a PLC isozyme remained a mystery for some time.

\section{PLCל as the putative oocyte activation factor}

Using mouse express sequence tag (EST) databases, Saunders et al. (2002) successfully identified a novel testis-specific PLC, termed PLCzeta (PLC)), a $\sim 74 \mathrm{kDa}$ protein which was proven to play a key role in oocyte activation [59]. Subsequent studies have identified further mammalian PLC $\zeta$ orthologues in human, hamster, monkey, and horse sperm [59,61-65], as well as in nonmammals such as chicken, fish, and quail [57,66-68].

Numerous studies support the contention that PLC $\zeta$ is the physiological agent responsible for $\mathrm{IP}_{3}$-mediated $\mathrm{Ca}^{2+}$ release in activating oocytes (Figure 2) [18,59,61]. Microinjection of both PLCל cRNA and recombinant protein into mouse and bovine oocytes resulted in the initiation of oscillations and oocyte activation, similar to that seen during normal fertilisation, and stimulated embryonic development to the blastocyst stage $[59,61,69-74]$. Injection of human PLCל cRNA also initiated $\mathrm{Ca}^{2+}$ oscillations in human oocytes and led to pre-implantation development [75]. Depletion of PLCל from sperm extracts [59], or the inhibition of PLCC expression in sperm using transgenic RNA interference [76], significantly abolished the ability to initiate $\mathrm{Ca}^{2+}$ release, or caused premature termination of $\mathrm{Ca}^{2+}$ oscillations and reduction in litter size.

Interestingly however, Coward et al. (2011) recently identified ovarian and brain isoforms of PLC $\zeta$ in puffer-fish (Takifugu rubripes) [68]. Injection of cRNA corresponding to the ovarian isoform into mouse oocytes did not induce $\mathrm{Ca}^{2+}$ oscillations [68]. It is possible that puffer-fish PLCל requires further oocyte- or sperm-based factors for $\mathrm{Ca}^{2+}$ inducing activity. Intriguingly, expression of puffer-fish PLCל was also observed within the brain. This was particularly surprising considering that PLCל is generally reported to be testis-specific [68]. While, Yoshida et al. (2007) reported the expression of PLC $\mathrm{mRNA}$ in the brain of both male and female mice [77], this directly contradicted the findings of Saunders et al. (2002) [59]. While it would be of interest to investigate the physiological relevance of PLC $\zeta$ isoforms in the brain, it would first be necessary to confirm these earlier findings using more rigorous methodology [68].

Although it is possible that the ovarian PLCל isoform in puffer-fish is an evolutionary adaption related to reproductive strategy, this discovery was particularly interesting given the debate regarding the mechanism responsible for oocyte activation $[19,35,68,78]$. Recent studies have proposed alternative sperm factor candidates apart from PLCל, which are able to induce meiotic progression or the typical pattern of $\mathrm{Ca}^{2+}$ oscillations in a variety of species. Sette et al. (1997) previously identified the truncated c-kit (tr-kit), enriched in mouse sperm, as being an oocyte activation factor demonstrating meiotic resumption and mouse oocyte activation on microinjection of extracts expressing recombinant tr-kit [79]. Harada et al. (2007) identified citrate synthase as the major component responsible for egg activation in the newt Cynops pyrrhogaster [80], however, citrate synthase is not a proposed oocyte activation factor in mammals. Wu et al. (2007) also reported another possible candidate for the sperm factor, residing in the post-acrosomal sheath region of the perinuclear theca, termed post-acrosomal sheath WW domain-binding protein (PAWP), in bovine sperm and other mammalian species [81]. Despite PAWP and citrate synthase representing alternative candidates to PLC $\zeta$ as the oocyte activation factor, the precise molecular mechanisms underlying the function of both proteins remain unknown, with no demonstration of the proteins triggering $\mathrm{Ca}^{2+}$ oscillations in mammalian oocytes casting doubt over their candidacy of being the mammalian oocyte activation factor [82]. While it is possible that oocyte activation involves the collective action of PLCל and other sperm factors, such theories remain to be established [3]. Furthermore, it is also possible that oocyte-borne factors, similar to puffer-fish PLC $\zeta$, may contribute towards the activation mechanism.

Current data provides evidence that PLC $\zeta$ represents a factor that is crucial to the process of mammalian oocyte activation. Consequently, this protein has been the target of a series of molecular and biochemical studies over recent years. PLC $\zeta$ exhibits a typical PLC domain structure [59] with characteristic $X$ and $Y$ catalytic domains which form the active site in all PLC isoforms $(\beta, \gamma, \delta, \epsilon$ and $\eta)$ [83-85], a single C2 domain and four tandem EF hand domains. PLC $\zeta$ exhibits closest homology with PLC $\delta$, with $33 \%$ similarity [59]. However, one major difference to other PLCs is the absence of pleckstrin homology $(\mathrm{PH})$ and Src homology $(\mathrm{SH})$ domains, making PLCל the 


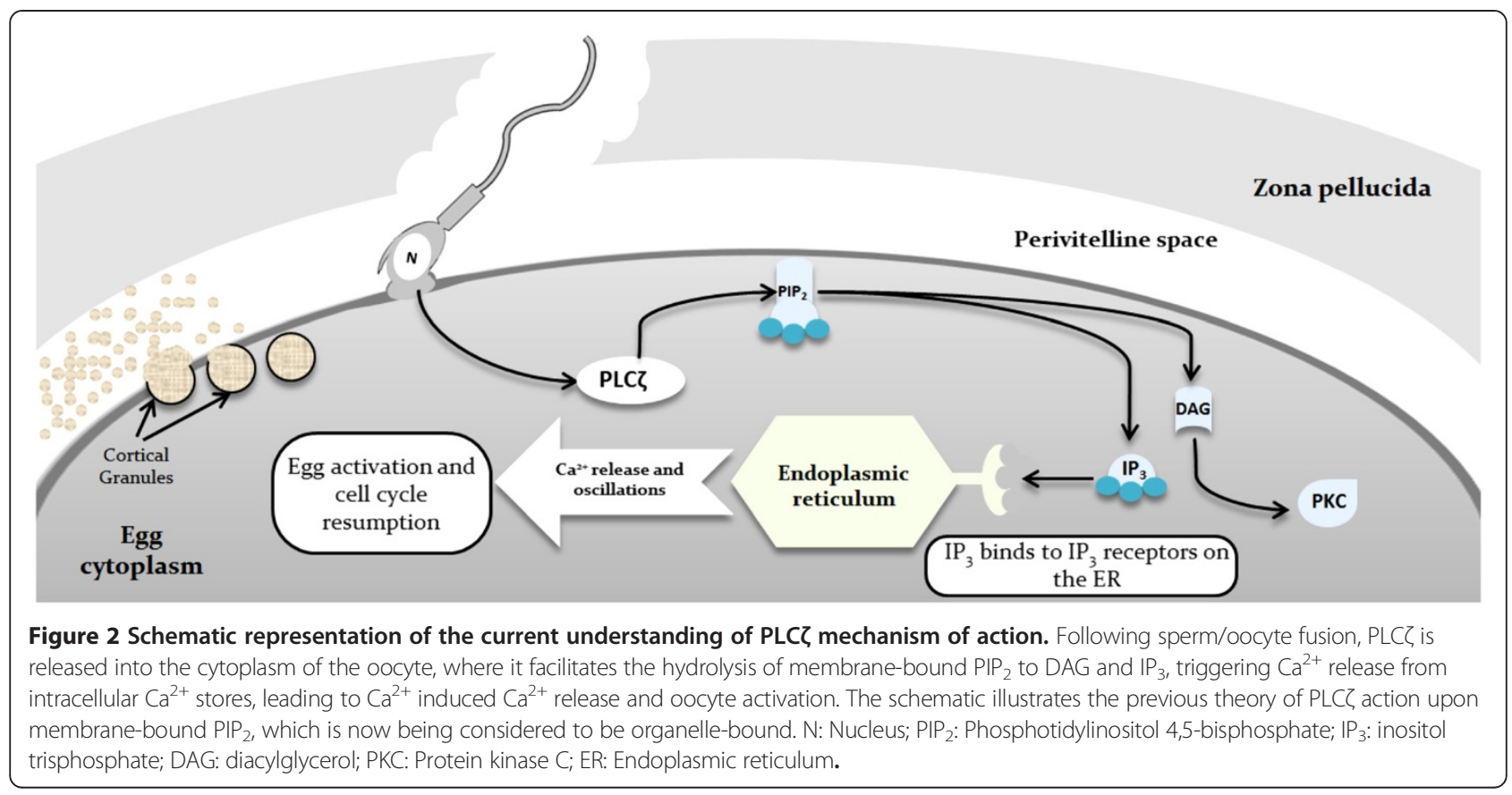

smallest known mammalian PLC with a molecular mass of $\sim 70 \mathrm{kDa}$ in humans and $\sim 74 \mathrm{kDa}$ in mice (Figure 3) [59]. Another distinctive feature of PLC $\zeta$ is its high sensitivity to $\mathrm{Ca}^{2+}[69]$. The catalytic XY domain is highly conserved, showing close homology with PLC $\delta$, and mutagenesis of active site residues leads to total loss of $\mathrm{Ca}^{2+}$-oscillatory ability $[33,86-88]$. However, the X-Y linker region is poorly conserved amongst $\mathrm{PLC} \zeta$ isoforms, except for the presence of positively charged amino acids, prompting speculation that differing motifs in this region may underlie species-specific patterns of $\mathrm{Ca}^{2+}$ oscillations amongst mammals $[33,36,89]$. Nomikos et al. (2011) recently suggested that these charged amino acids may play an important role in the interaction of PLC $\zeta$ with $\mathrm{PIP}_{2}$ $[87,90,91]$. Yu et al. (2011) further demonstrated that whilst PLC $\delta$ targets $\mathrm{PIP}_{2}$ at the oolemma, mouse PLCל appeared to target intracellular membranous $\mathrm{PIP}_{2}$ on distinct vesicular structures within the mouse oocyte cortex [92]. Moreover, fluorescently-tagged human recombinant PLC $\zeta$ indicated localisation to discrete regions within the cell cytoplasm when expressed in HEK293T cells, adjacent to the nuclear envelope, possibly representing a specific organelle sub-type [74]. In accordance with these findings, mouse PLCל remains in an inactive state and fails to induce $\mathrm{Ca}^{2+}$ oscillations in the $\mathrm{CHO}$ cell line, which are known to be devoid of organelle-bound $\mathrm{PIP}_{2}$ [93].

As well as providing evidence for the $\mathrm{Ca}^{2+}$ releasing target of PLC $\zeta$, this also suggests that specific factors within the ooplasm may be required for PLC -mediated $\mathrm{Ca}^{2+}$ release [93]. However, Kashir et al. (2011a) demonstrated that

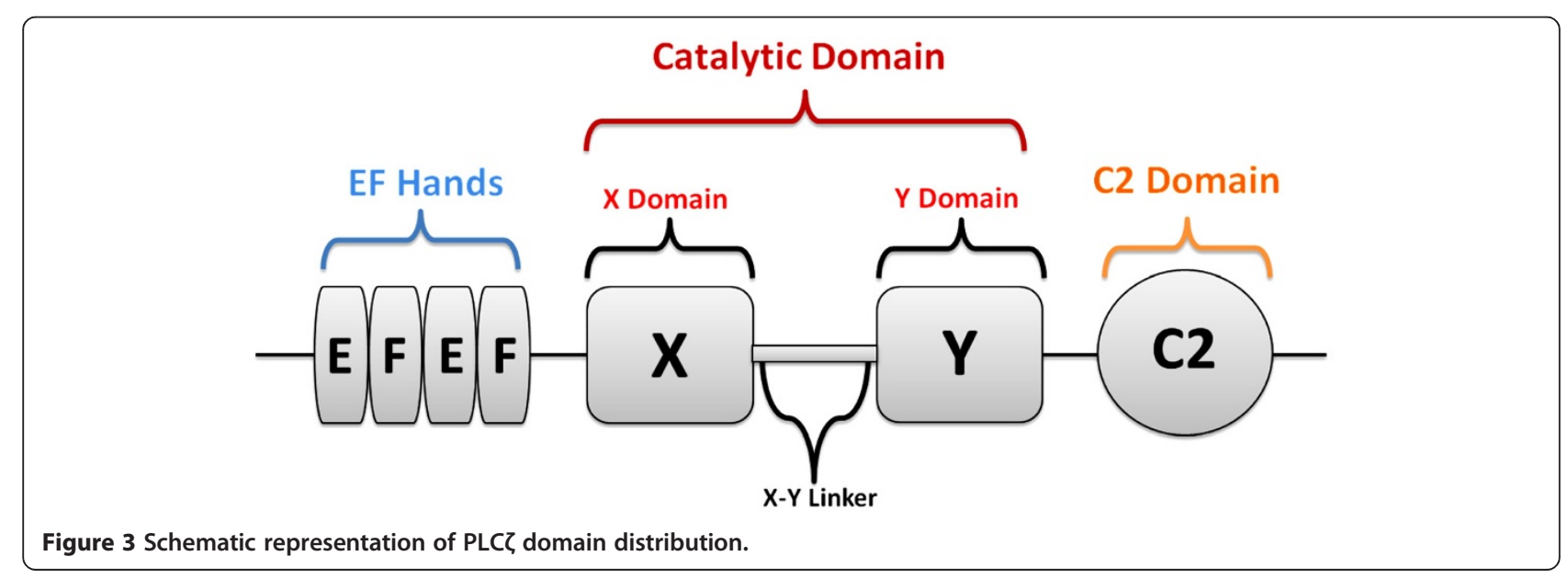


recombinant human PLC $\zeta$ was expressed in an active state within HEK293T cells, and maintained activity following injection of transfected HEK293T lysates into mouse oocytes [74]. Furthermore, there was a clear delay between lysate injection and the initiation of $\mathrm{Ca}^{2+}$ oscillations, possibly indicating that oocyte-based mechanisms resulted in the modification of recombinant PLCל, ultimately resulting in an active state [74]. It is possible that these differences are due to inter-species variance, or the type of mammalian cells deployed in laboratory-based experiments. Indeed, human PLCל has been shown to be much more potent in terms of PLC activity compared to the mouse isoform $[3,33,35,59,61,71]$. It also remains possible that HEK293T cells contain molecular mechanisms not present within $\mathrm{CHO}$ cells, which ultimately led to the presence of active PLC $\zeta$. Collectively, these studies provide significant insight into the mechanism of action of PLC $\zeta$, and demonstrate the importance of continued research effort, particularly with regard to the activation of human oocytes.

A sequence of amino acids predicting a nuclear localisation signal (NLS) was identified in the X-Y linker region of mouse PLCל, thought to be a binding site of the nuclear transport receptor, which may play a role in regulating PLC activity. The distribution of PLC $\zeta$ within the activating mouse oocyte changes during the first cell cycle, exhibiting PN localisation during zygotic interphase [66,94-97] thereby restricting access of the enzyme to its substrate $\mathrm{PIP}_{2}$, and thus resulting in termination of $\mathrm{Ca}^{2+}$ oscillations. Mutation of this putative NLS sequence prevented nuclear accumulation, as well as the termination of oscillations at interphase [33,95]. Kuroda et al. (2006) hypothesised that PLC $\zeta$ is driven into the nucleus primarily by the NLS [98]. Close contact with EF/C2 domains appears to be required not only for enzymatic activity but also for nuclear translocation ability $[69,96,99,100]$.

However, the injection of human, bovine, rat or medaka fish PLCל into mouse oocytes does not result in PN translocation $[64,66,97]$. It is not yet clear whether human PLC $\zeta$ has a distinctive NLS sequence, although nuclear localisation may prove to be the result of a conformational change or modification arising from interaction with other, as yet unknown, adaptors. It is worth noting that Ito et al. (2008) demonstrated nuclear localisation of human and mouse PLC $\zeta$ in COS-7 cells, and that Coward et al. (2006) observed localisation of mouse PLC $\zeta$ to either the nucleus or cytoplasm of COS cells [101]. In a more recent study, Kashir et al. (2011a) detected cytoplasmic localisation of human PLC\ when expressed in HEK293T cells [74]. While there seems to be conflicting evidence in this regard, the observed lack of nuclear localisation could reflect either the cell type used, or the reduced nuclear localisation activity of human PLCC compared to mouse. It may also be the case that functional disparities may exist between the mouse NLS, as well as any potential human NLS. However, the existence, and functional significance if any, of the human PLC $\zeta$ NLS must be confirmed before any such comparison can be made.

Upon PN envelope breakdown during entry into mitosis, $\mathrm{Ca}^{2+}$ oscillations resume $[11,94-96,102]$ and may act in conjunction with modifications to the $\mathrm{IP}_{3}$ receptor to terminate $\mathrm{Ca}^{2+}$ signals at fertilisation $[31,95]$. Sone et al. (2005) showed that this pattern of PLC $\zeta$ expression continues beyond first mitosis by exogenously expressing PLC $\zeta$ at later stages of embryo development, showing continued nuclear sequestration of PLC $\zeta$ during mitotic proliferation [103]. Thus, shuttling of PLCל between the cytoplasm and nucleus appears to be strongly related to the termination/resumption of $\mathrm{Ca}^{2+}$ oscillations in a cellcycle dependent manner, suggesting a possible role for PLC $\zeta$ in mediating the cell-cycle dependency of $\mathrm{Ca}^{2+}$ oscillations in the early embryo [103]. Since no other species share the ability of mouse PLC $\zeta$ s for nuclear translocation, it remains unclear whether this is a widespread phenomenon in mammals, or whether it holds any physiological importance.

PLC $\zeta$ is thought to remain in an inert state within sperm, and once introduced into the oocyte by gamete membrane fusion, becomes enzymatically active [33]. It is currently unclear how such a physiologically active protein is maintained in an inert form within sperm. Studies indicate that there may be an oocyte component that is necessary for the activation process [74,77,93]. Elucidation of what the oocyte factors are may explain how PLC $\zeta$ is maintained in an inactive state in the sperm but is activated on release into the oocyte. It is possible that PLC $\zeta$ needs to undergo post-translational modifications before reaching an active state [64]. Indeed, spontaneous proteolysis of PLC $\zeta$ was apparent in both mouse and porcine sperm $[89,104]$, with cleaved products re-associating to form functional heterodimers with increased levels of activity [89]. Moreover, a $62 \mathrm{kDa}$ PLC $\zeta$ isoform lacking EF1-3 hand domains was previously described in mouse sperm $[69,89,99,104,105]$, and reported to activate mouse oocytes and support normal development to term [100]. Intriguingly, purified recombinant mouse PLC $\zeta$ did not undergo cleavage, retained activity in-vitro, but was far less efficient at inducing $\mathrm{Ca}^{2+}$ oscillations in mouse oocytes $[69,99,105]$. It is vital, therefore, that future studies elucidate whether post-translational or covalent modifications such as cleavage are a necessary requirement for endogenous PLC $\zeta$ activity.

There appears to be significant species-specific differences in the concentration and activity of PLC $\zeta$ delivered into oocytes during fertilisation, allowing for the different specific requirements of each species, and the specific $\mathrm{Ca}^{2+}$ oscillation pattern leading to embryo development [64]. PLC $\zeta$ has been detected in sperm from many species, and is localised to distinct regions in the sperm head, with 
suggestions of differential functional roles for each population $[3,63,106]$. Three distinct populations of PLC $\zeta$ have been identified in the human sperm head; acrosomal, equatorial and post-acrosomal $[85,106,107]$, whereas in mouse and boar sperm, two populations have been identified acrosomal and post-acrosomal [63,108,109]. In equine sperm, PLC $\zeta$ was reported to be localised to the acrosome, equatorial segment and head mid-piece, as well as principle piece of the flagellum [65]. In the pig, PLCל was identified in the post-acrosomal region, and the tail [110].

Young et al. (2009) demonstrated dynamic changes of PLC $\zeta$ localisation in mouse sperm following capacitation and the acrosome reaction [63]. Prior to capacitation, both populations were present, with the acrosomal population being more prominent, and following capacitation, sperm showed post-acrosomal localisation only. Grasa et al. (2008) echoed the findings of Young et al. (2009) in capacitated and non-capacitated fertile human sperm, but described three distinct populations of PLC $\zeta$ suggesting differential roles for each population [106] (Figure 4). Furthermore, Bi et al. (2009) identified an isoform of PLCל, which they inexplicably termed NYDSP27, found in the acrosome of human and mouse sperm [111]. These authors suggested that this protein was necessary for capacitation and the acrosome reaction, functioning as an intrinsic decapacitation factor. However, further evidence of this intriguing possibility has yet to be forthcoming.

Grasa et al. (2008) indicated that PLCל was predominantly localised to the equatorial region of human sperm, with relatively smaller populations in the acrosomal and post-acrosomal regions [106]. While it is not yet clear whether a particular pattern of localisation is required, or

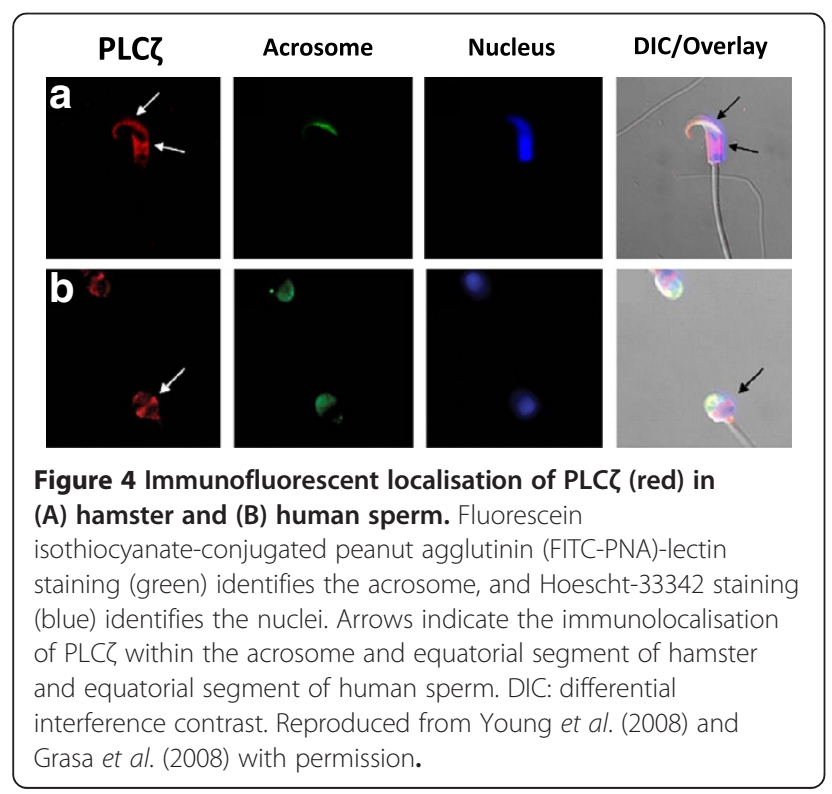

whether a combination of different populations is required for functional ability, the equatorial and post-acrosomal populations would indeed permit rapid access to the ooplasm following sperm-oocyte fusion [112-114]. Indeed, post-acrosomal populations of PLC $\zeta$ have also been identified in mouse, hamster, bull, pig, and boar sperm $[63,102,106,108-110]$. Furthermore, the presence of the post-acrosomal population of PLCל following in-vivo induced acrosome reaction provides further credence to a specific role for this protein in oocyte activation, as the factor responsible would be expected to be retained following this important physiological process $[63,106]$.

It has yet to be confirmed as to whether the population of PLC $\zeta$ in the acrosomal region of sperm plays a role in the acrosome reaction as some studies suggest [63,106,111]. Aghajanpour et al. (2011) suggest that the localisation of PLC $\zeta$ to the acrosome may be independent of PLC $\zeta$ mRNA expression, suggesting that the observed reduction in expression of PLC $\zeta$ mRNA in globozoospermic sperm may be related to other factors and not absence of the acrosome [115]. While it is possible that the acrosomal population plays a role in fertilisation, questions regarding the timing of the acrosome reaction relative to sperm-oocyte fusion [116] indicate that further work is required before such assertions are made. Understanding the relative roles of differential populations of PLC $\zeta$ will be essential prior to the use of this protein clinically, and should thus be the focus of future research directives. However, it is important to note that the polyclonal nature of all PLC $\zeta$ antibodies used thus far may explain the variance in localisation patterns observed between existing studies. Indeed, Aarabi et al.

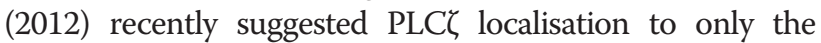
acrosomal and post-acrosomal regions of mouse, boar, and human sperm [117]. While the specificity of this particular antibody was previously confirmed by Grasa et al. (2008) in human sperm [106], immunoblotting results from the study by Aarabi et al. (2012) also appeared to identify crossreactivity with unidentified proteins other than PLCל [117]. Furthermore, considering that Grasa et al. (2008) suggested variance in predominant localisation patterns amongst fertile males (sperm from 6 human males), specific conclusions cannot be drawn from the relatively smaller sample size (sperm from 3 human males and 1 mouse) examined by Aarabi et al. (2012). However, it is imperative that efforts are directed towards the synthesis of more specific monoclonal antibodies against PLC $\zeta$ before conclusive remarks regarding variant isoforms and localisation patterns of PLCל may be made.

PLCᄃ mRNA expression and the initiation of translation have been identified during early and late stages of spermatogenesis in mice and pigs $[62,63,65,109,118]$. PLC $\zeta$ mRNA has also been identified in ejaculated human sperm [115,119-121]. While injection of PLCל cRNA into the oocyte induces the production of PLCל 
protein [59], the functional role of PLCל mRNA in the zygote remains to be ascertained. Considering there is a considerable difference in sperm mRNA content between fertile and infertile individuals [122], it seems plausible to consider that similar differences may apply to PLCל, with consequential repercussions on fertility.

\section{Links between PLC and male-factor infertility}

Deficiency in the mechanism of oocyte activation is regarded as the principal cause of fertilisation failure following ICSI, accounting for an estimated $40 \%$ of failed cases [3,123-125]. However, ICSI addresses only one of the necessary requisites for successful fertilisation, that of sperm penetration, whereas a range of post-penetration events are crucial for successful fertilisation [126]. The aetiology of ICSI failure in such cases is likely to be multifactorial in nature, and may be attributable to factors in the oocyte since the inherent quality of the oocyte is of great importance for successful fertilisation. Such factors would thus be reliant upon the fidelity of oocyte maturation, such as the inadequate sensitisation of $\mathrm{IP}_{3}$ receptors and ER $\mathrm{Ca}^{2+}$ concentration regulation required for optimal sperminitiated $\mathrm{Ca}^{2+}$ release $[11,127-129]$, or a reduction in the number of CG due to premature release, resulting in early blockade to polyspermy prior to insemination $[20,130]$. The suggestion that oocyte quality plays a role in fertility is further strengthened by a recent study reporting that the process of vitrification in ART affects the distribution of $\mathrm{IP}_{3} \mathrm{Rs}$, with subsequent detrimental effects upon $\mathrm{Ca}^{2+}$ oscillatory activity and embryo development, thus providing an explanation for low rates of blastocyst formation following ICSI treatment using vitrified oocytes compared to fresh oocytes [50].

Sperm defects however, are considered the leading cause of activation failure [3], and given the role of PLC $\zeta$ as the oocyte activating factor; it is highly plausible that defective forms, or abnormal function, of PLCל may be the underlying cause of certain types of male-factor infertility and oocyte activation failure. Indeed, evidence indicates that the severity of sperm defects, opposed to sperm source, determines the efficacy of ICSI success [131]. Much evidence now exists to highlight PLCऍ's role in fertility and relative role in male-factor infertility. Sperm from infertile men which consistently fail IVF and ICSI, also fail to induce $\mathrm{Ca}^{2+}$ oscillations upon injection into mouse oocytes, or cause abnormal patterns of $\mathrm{Ca}^{2+}$ release when compared with those of fertile males $[86,107]$ (Figure 5A). Such sperm also exhibited absent/ reduced levels, or abnormal isoforms, of PLCל (Figure 5B) $[86,107]$.

The first genetic link between PLC $\zeta$ and oocyte activation deficiency (OAD) was reported by Heytens et al. (2009), who identified a substitution mutation in an infertile male diagnosed with OAD [86]. This involved a substitution of a histidine to proline within the $\mathrm{Y}$ domain of the catalytic site of the protein, at position 398 of the PLC $\zeta$ open reading frame (PLC $\left.\zeta^{\mathrm{H} 398 \mathrm{P}}\right)$. Micro-injection of PLC $\zeta^{\mathrm{H} 398 \mathrm{P}} \mathrm{cRNA}$ into mouse oocytes failed to induce $\mathrm{Ca}^{2+}$ oscillations, whilst the injection of sperm possessing this mutation resulted in an atypical pattern of $\mathrm{Ca}^{2+}$ oscillations [86]. An equivalent mutation was subsequently created for mouse PLC $\zeta$ (PLC $\zeta^{\mathrm{H} 435 \mathrm{P}}$ ) [88]; murine experiments confirmed that this mutation caused major structural changes to the PLC $\zeta$ protein, resulting in functional inactivation.

More recently, Kashir et al. (2012) identified a further novel point mutation from the same patient from whom the H398P mutation was first identified, involving a substitution of a histidine to leucine residue in the catalytic $\mathrm{X}$ domain at position 233 of the PLC open reading frame $\left(\mathrm{PLC} \zeta^{\mathrm{H} 233 \mathrm{~L}}\right)$ [132]. Micro-injection of PLC ${ }^{\mathrm{H} 233 \mathrm{~L}}$ cRNA resulted in an abnormal $\mathrm{Ca}^{2+}$ release profile and like the H398P mutation, a failure to activate oocytes (Figure 6) [132]. Interestingly, this study also showed that both the $\mathrm{PLC} \zeta^{\mathrm{H} 398 \mathrm{P}}$ and $\mathrm{PLC} \zeta^{\mathrm{H} 233 \mathrm{~L}}$ mutations, which are heterozygous in nature, originated from different parental origins: $\mathrm{PLC}^{\mathrm{H} 398 \mathrm{P}}$ was paternal in origin, while PLC $\zeta^{\mathrm{H} 233 \mathrm{~L}}$ was maternal. These findings represented the first description of an autosomal point mutation resulting in male fertility via the maternal lineage [132]. Furthermore, albeit speculation at present, Kashir et al. (2012) hypothesised that mutations in PLCל may be recessive in nature, requiring mutation on both parental alleles for full infertility to occur. One would also reason that heterozygous mutations in PLCל may result in cases of sub-fertility. Indeed, Kashir et al. (2011a) reported that HEK293T cells overexpressing fluorescently-tagged $\mathrm{PLC} \zeta^{\mathrm{H} 398 \mathrm{P}}$ exhibited a lower level of fluorescence compared to HEK293T cells over-expressing fluorescent-PLC $\zeta^{\mathrm{WT}}$, correlating to absent/severely reduced levels of PLC $\zeta$ in sperm from the patient from whom the H233L and H398P mutations were identified [74].

Furthermore, absent/reduced levels of PLCל in sperm have been implicated in forms of male infertility where such sperm is repeatedly unable to activate oocytes $[86,107,133]$. It is therefore possible that cases in which PLC $\zeta$ is absent or severely reduced may be due to destabilising effects caused by mutation in highly conserved

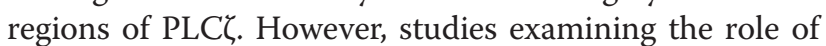
deletions in critical domains essential to mouse PLCC function did not report any differences in protein stability $[89,105]$. Furthermore, considering that sperm and HEK293T cells may exhibit very different molecular mechanisms, it is important that future studies examine the effect of mutant PLC $\zeta$ in testicular germ cells to investigate whether such a trend is repeated, and to determine whether such loss-of-activity mutations are potentially disruptive to the overall folding of PLCל. 


\section{a}

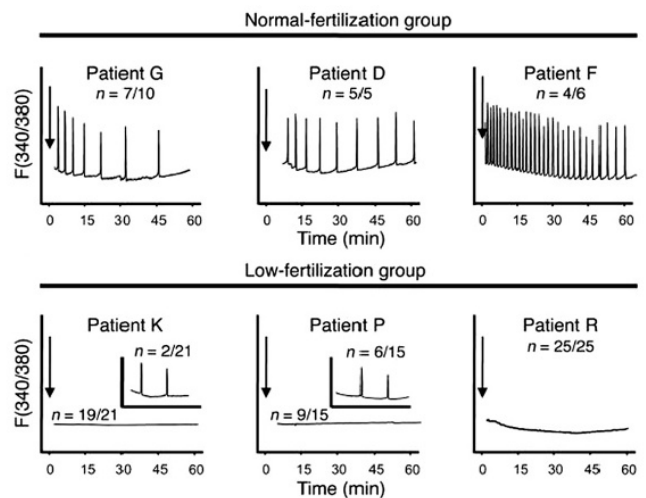

b

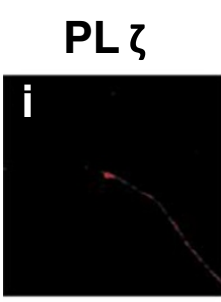

Acrosome

Nucleus

DIC/Overlay
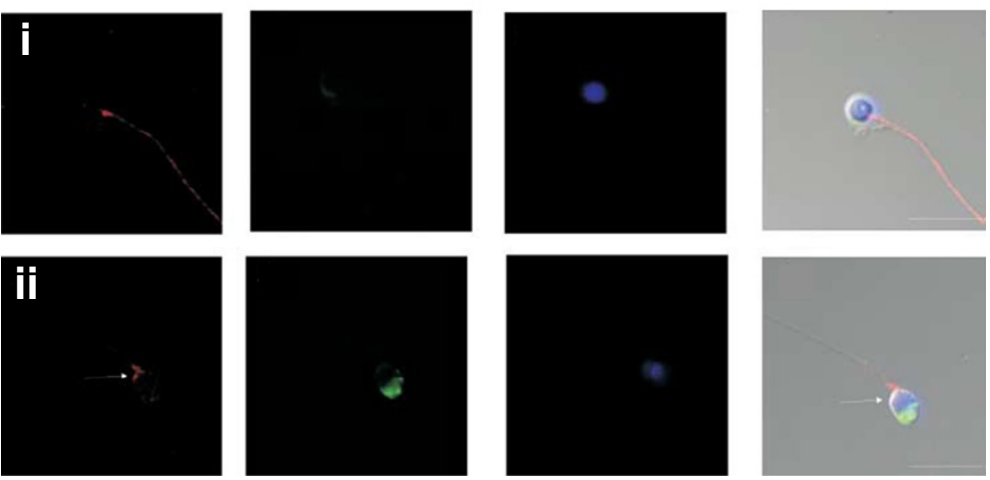

Figure 5 A) $\mathrm{Ca}^{2+}$ oscillation profiles following the injection of sperm from normal fertile humans (top panel) and infertile patients who had previously failed or exhibited low fertilisation rates following ICSI (bottom panel). Arrows denote time of sperm injection, and $n$ indicates the number of mouse oocytes exhibiting the corresponding $\mathrm{Ca}^{2+}$ oscillation profile. B) Reduced PLCZ immunostaining (red) in sperm from infertile ICSI failed patients exhibiting abnormal morphology (in this case globozoospermia; acrosome-less, round-headed sperm) (i), and normal morphology (ii). Fluorescein isothiocyanate-conjugated peanut agglutinin (FITC-PNA)-lectin staining (green) identifies the acrosome, and Hoescht-33342 staining (blue) identifies the nuclei. Arrow indicates reduced PLC immunolocalisation within the equatorial segment. Scale bars indicate $5 \mu \mathrm{m}$. Reproduced from Yoon et al. (2008) and Heytens et al. (2009) with permission.

The therapeutic potential of PLCל for ART

Although ICSI results in average fertilisation rates of $70 \%[3,134]$, complete or virtually complete fertilisation failure still occurs in $1-5 \%$ of ICSI cycles [3,9,124,135], corresponding to approximately 1000 cases per year in the UK alone. The incorrect injection of sperm, expulsion of injected sperm from the oocyte, and the failure of sperm head decondensation are not considered to contribute substantially to fertilisation failure following ICSI $[3,9]$. A deficiency in the mechanism of oocyte activation is regarded as the principal cause of fertilisation failure, or abnormally low fertilisation after ICSI, and can recur in successive ART cycles [3,123,136]. At present, such cases can only be resolved using assisted oocyte activation (AOA).

Cases of oocyte activation failure can currently be treated by $\mathrm{AOA}$ methods such as $\mathrm{Ca}^{2+}$-ionophore or strontium chloride $[9,133,136,137]$. The most popular artificial activating agents for human oocytes include $\mathrm{Ca}^{2+}$ ionophores such as ethanol, ionomycin and A23187, electrical pulses, often in combination with protein synthesis or kinase inhibitors such as 6-dimethylaminopurine (6DMAP) or puromycin that block the re-synthesis of cyclin B or CDK1 activity [136]. Taylor et al. (2010) demonstrated high rates of fertilisation, and successful pregnancy, in PLCל-deficient globozoospermic patients using a $\mathrm{Ca}^{2+}$ ionophore to artificially activate the oocytes following ICSI [133]. However, there is significant concern as to how such chemicals may be detrimental to embryo viability and future health due to potential cytotoxic, mutagenic and teratogenic effects on oocytes and embryos [6]. $\mathrm{Ca}^{2+}$ release patterns following ionophore treatment do not mimic those observed during normal fertilisation (Figure 7) [86]. Consequently, the abnormal $\mathrm{Ca}^{2+}$ signal induced, which 


\section{a}
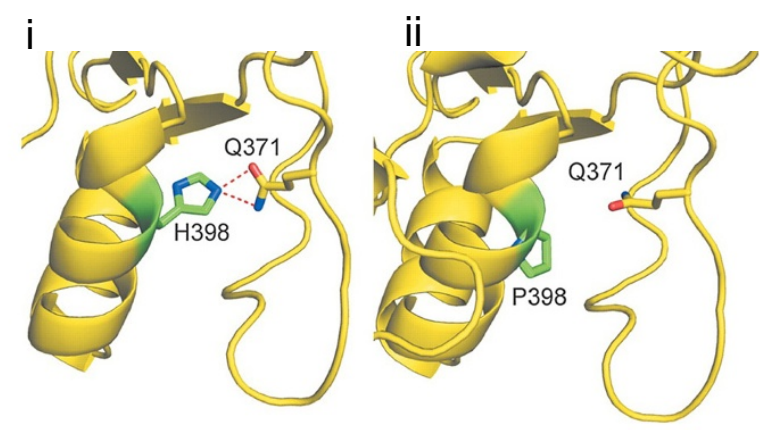

b

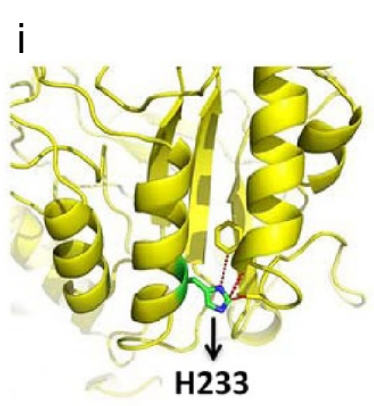

ii

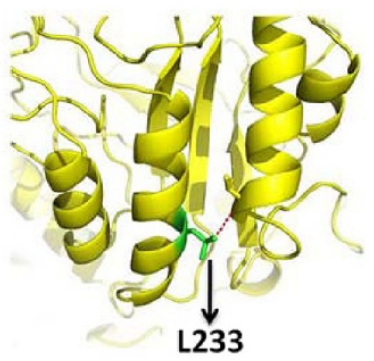

C
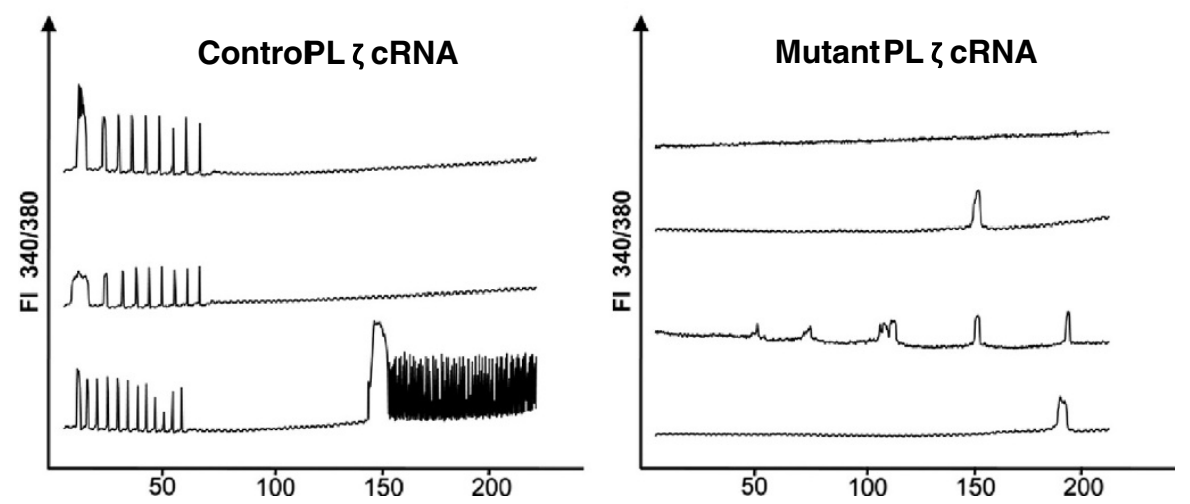

Figure 6 Schematic representations of the effects of the Histidine $>$ Proline $\left(P L C \zeta^{\mathrm{H} 398 \mathrm{P}}\right)(\mathrm{A})$ and Histidine $>$ Leucine $\left(\mathrm{PLC} \zeta^{\mathrm{H} 233 \mathrm{~L}}\right)(\mathrm{B})$ point mutations identified by Heytens et al. (2009) and Kashir et al. (2012) in an infertile male patient diagnosed with oocyte activation deficiency. For both A) and B), schematics represent local protein folding before mutation (i) and after mutation (ii). C) Microinjection of wild type and mutant PLCל into mouse oocytes and resulting calcium release patterns. FI 340/380: ratio of fluorescence at wavelengths of 340 nm and $380 \mathrm{~nm}$. Reproduced from Heytens et al. (2009) and Kashir et al. (2012) with permission.

often manifests as a single $\mathrm{Ca}^{2+}$ transient, is a potential threat to ensuing development at later stages $[45,138]$, with potential repercussions on epigenetic processes [139]. Moreover, the threat is increased in cases of AOA with abnormal sperm such as in cases of globozoospermia, due to the high degree of sperm DNA fragmentation associated with this pathology $[133,139,140]$. Other activating agents have been shown to induce multiple transients, such as strontium chloride in mice [14,141], phorbol esters [141] or thimerosal [142]. These, however, have only been reported to be efficient in a limited number of species, are less efficient than ionophores in most species, or can cause meiotic spindle disruption [143].

The most efficient of these is Strontium $\left(\mathrm{Sr}^{2+}\right)$, which was found to elicit $\mathrm{Ca}^{2+}$ oscillations through the synergistic action of PLC activation and $\mathrm{IP}_{3}$ activity mediation via $\mathrm{IP}_{3}$ receptor sensitisation to release $\mathrm{Ca}^{2+}$ [144], the use of which resulted in successful pregnancy of normozoospermic patients diagnosed with OAD [145]. However, $\mathrm{Sr}^{2+}$ treatment varies in terms of oocyte activation efficacy depending on the species in which it is used [9] with success rates being relatively low in humans [145]. 

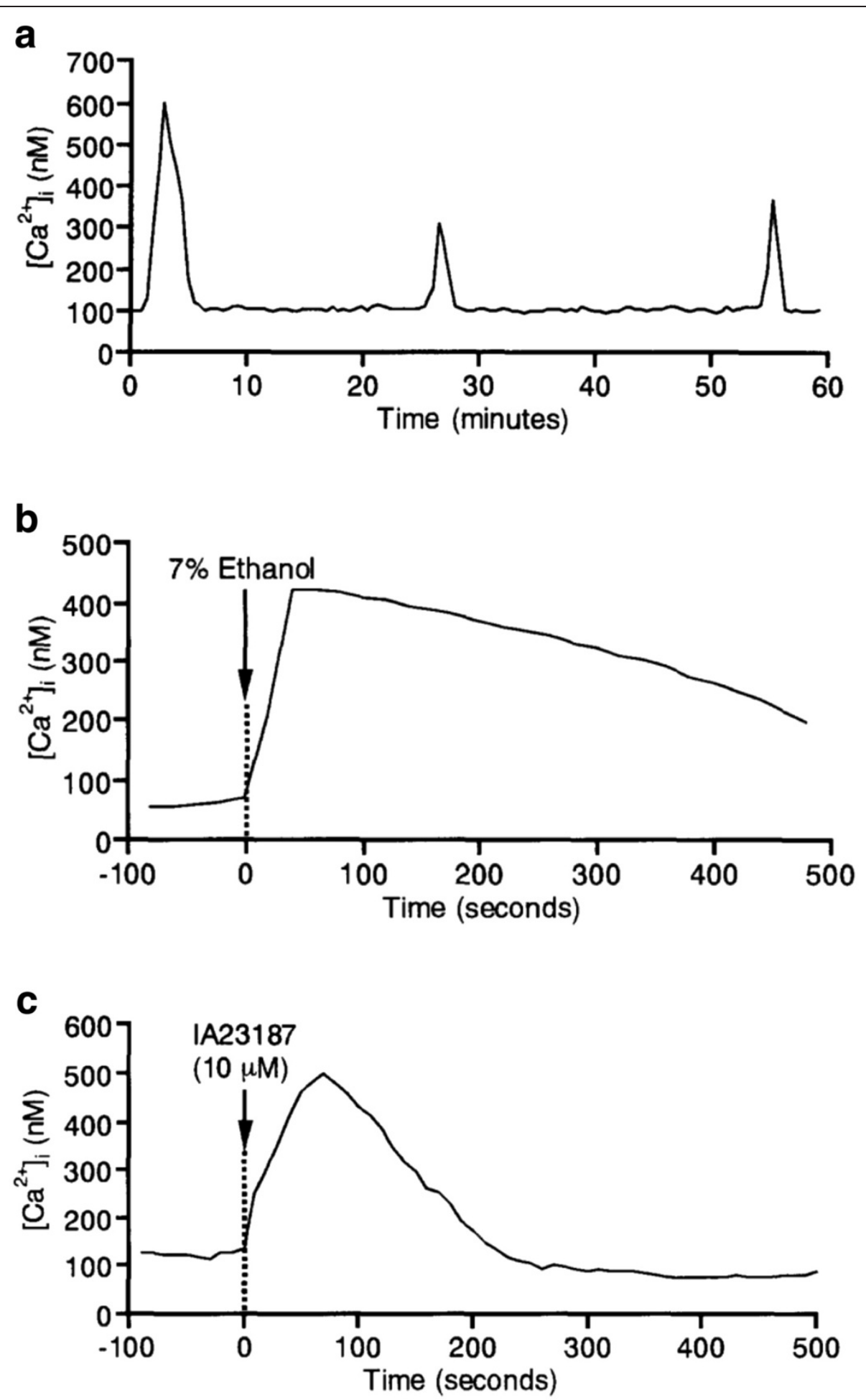

Figure 7 Representative $\mathrm{Ca}^{2+}$ responses of bovine oocytes treated with A) sperm (normal fertilisation), B) $7 \%$ ethanol, and C) $\mathrm{Ca}^{2+}$ ionophore IA23187. Reproduced from Nakada and Mizuno (1998) with permission.

Furthermore, little is currently known as to the downstream effects of $\mathrm{Sr}^{2+}$ treatment on signalling molecules such as PKC and DAG. It would, therefore, be prudent to investigate and develop new methods of AOA which elicit $\mathrm{Ca}^{2+}$ release in an endogenous manner, to circumvent these concerns for clinical scenarios. An ideal 
example would be a purified recombinant version of human PLC $\zeta$ protein, the principle of which has been previously demonstrated by Yoon et al. (2008) using mouse cRNA [107].

Yoon et al. (2008) showed that the failure of sperm exhibiting abnormal PLCC localisation to activate an oocyte could be rescued upon co-injection with mouse PLC $\zeta$ mRNA (Figure 8) [107], while Rogers et al. (2004) showed that it was possible to generate blastocysts parthenogenetically following the injection of PLC $\zeta$ cRNA into human oocytes [75], providing significant support for the clinical use of PLCY as a therapeutic. However, the therapeutic utilisation of PLC $\zeta$ cRNA is not likely to be viable, since the uncontrollable transcription of PLC $\zeta$ may be detrimental to normal pre-implantational development through gene expression irregularities, with developmental defects observed in some embryos $[16,45,75]$. Moreover, injected PLCל RNA could potentially be reverse transcribed into cDNA which may then be incorporated into the genome $[3,146]$. It follows therefore, that an active, purified, recombinant version

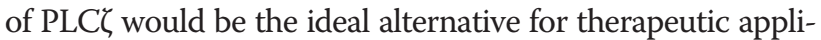
cation in the clinic, as it would function in a safe and endogenous manner.

Consequently, the synthesis of a pure and active recombinant form of PLC $\zeta$ has been a key goal over recent years. However, this has proved far more difficult than first perceived. Purification, in particular, tends to be tenuous with previous studies culminating in an inactive protein following purification. This suggests either that the purification process itself renders the protein inactive, or that the laboratory processes involved did not permit key post-translational modifications or proteinfolding mechanisms [64]. Kouchi et al. (2004) successfully purified a mouse recombinant PLC $\zeta$ protein which exhibited high $\mathrm{Ca}^{2+}$ sensitivity and induced $\mathrm{Ca}^{2+}$ oscillations upon injection into mouse oocytes [69]. However, these oscillations were of a much higher frequency than those seen during normal fertilisation and have proved difficult to replicate thereafter. More recently, Phillips et al. (2011) demonstrated that a cell lysate prepared from $\mathrm{CHO}$ cells transfected with mouse PLC $\zeta$ exhibited high recombinant protein expression, and on microinjection into mouse oocytes, elicited $\mathrm{Ca}^{2+}$ oscillations representative of oocyte activation [93].

Until very recently, progress remained slow in extrapolating such techniques to the human protein. However, the use of a human cell line has finally yielded a cell lysate expressing a recombinant human PLC $\zeta$ protein which, upon injection into mouse oocytes, elicited $\mathrm{Ca}^{2+}$ oscillations characteristic to those seen in normal fertilisation [74]. While representing a significant milestone in the clinical translation of PLC $\zeta$ (Figure 9), there is still much to accomplish, given that activity was only evident in cell lysates, and not in a purified form.
Given that PLC $\zeta$ plays a fundamental role in the process of oocyte activation, it is logical to deliberate how this knowledge might assist with the generation of a male contraceptive agent for fertile males, for example by specifically blocking the physiological action of PLC $\zeta$. However, this is not without complication and a significant body of research would be required to pursue this goal, including elucidation of the three-dimensional structure of the protein. Given that PLC $\zeta$ has been detected in tissues and cells other than sperm in nonmammalian species [68], it would appear prudent to carry out wider scale expression studies to re-confirm that PLC $\zeta$ is specifically expressed in human sperm and not any other cell or tissue-type. While inactivation of the PLCC protein is theoretically possible, it is critical that new contraceptive agents are safe, reversible, effective, and specific in their mode of action upon target mechanisms. One particular caveat, is the fact that PLC $\zeta$ RNA has been identified in ejaculated sperm [115,120,121], suggesting that even if PLC $\zeta$ protein is inactivated in epididymal sperm, stocks of RNA remaining in the sperm may be able to contribute towards $\mathrm{Ca}^{2+}$ release [72,74,75,107]. While levels of PLC $\zeta$ RNA present in sperm may not be sufficient to lead to complete oocyte activation, these levels may contribute towards the overall pattern of $\mathrm{Ca}^{2+}$ release. Indeed, injection of human PLCC cRNA as low as $0.001 \mu \mathrm{g} / \mu \mathrm{l}$ and $0.02 \mu \mathrm{g} / \mathrm{ml}$ are able to result in $\mathrm{Ca}^{2+}$ release in mouse and human oocytes respectively $[61,74]$.

\section{PLCל as a prognostic biomarker of male fertility}

Semen analysis based on concentration, motility and morphology has been used for the diagnosis of male fertility for many years, using criteria for normal semen parameters established by the WHO [147]. However, a significant number of patients with normal sperm parameters still undergo difficulty in achieving successful pregnancy [148]. This reflects the complexity of the events involved in sperm function, indicating that analysis based on concentration, motility and morphology may not represent an entirely accurate tool to assess the fertilising potential of a sperm sample. Consequently, there is significant interest at present for the development of additional tests to complement existing analytical procedures. Recent studies have demonstrated the potential of measuring sperm nuclear DNA fragmentation and protamine deficiency in sperm samples by revealing significant differences between fertile and infertile sperm $[149,150]$.

It is conceivable that the quantitative analysis of PLC $\zeta$ within sperm may represent a rapid and informative diagnostic tool for both research and clinical purposes, by providing an indicator, or biomarker, of oocyte activation ability. A heterologous ICSI model, the mouse oocyte activation test (MOAT), was previously developed to evaluate 


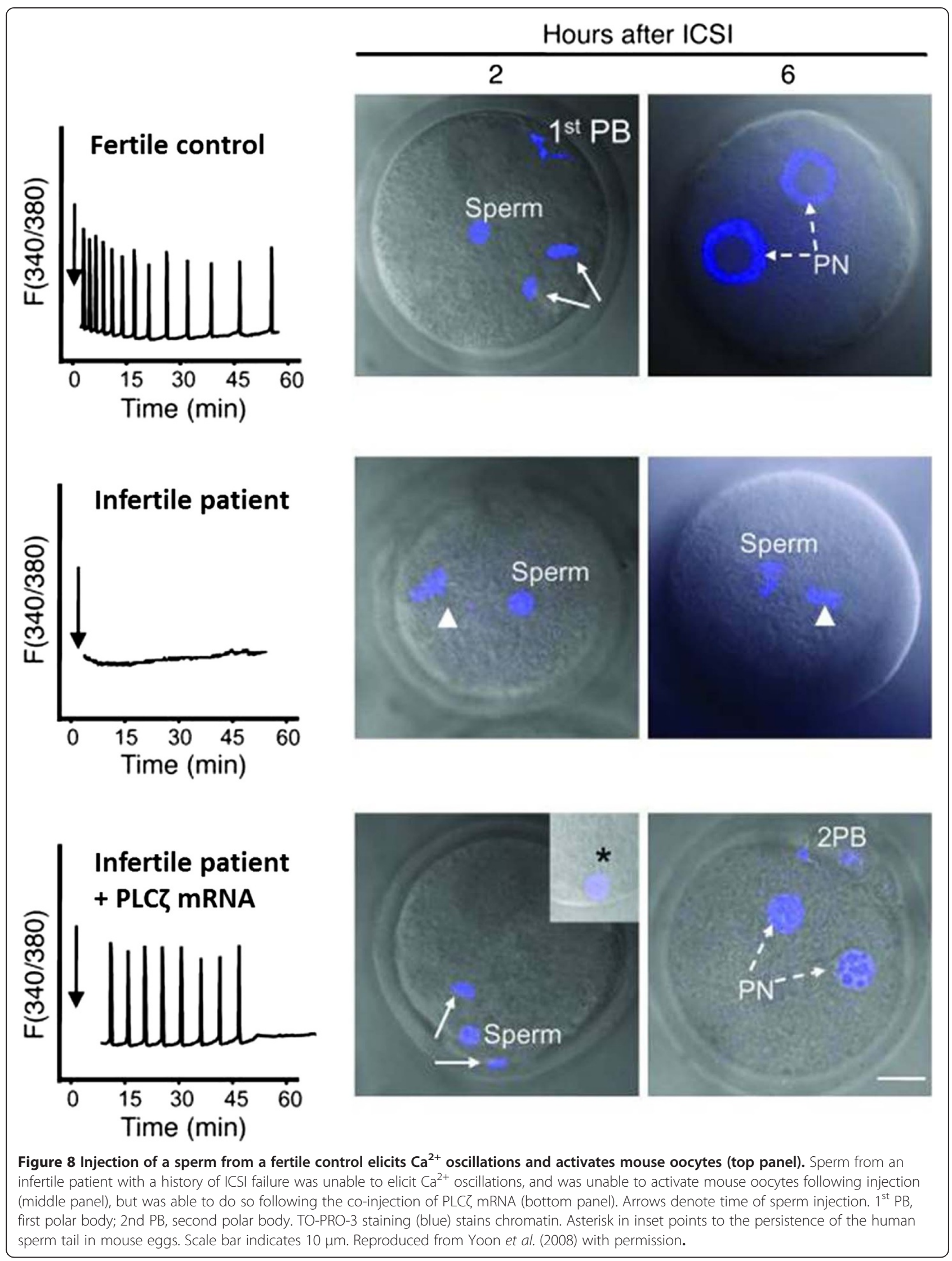




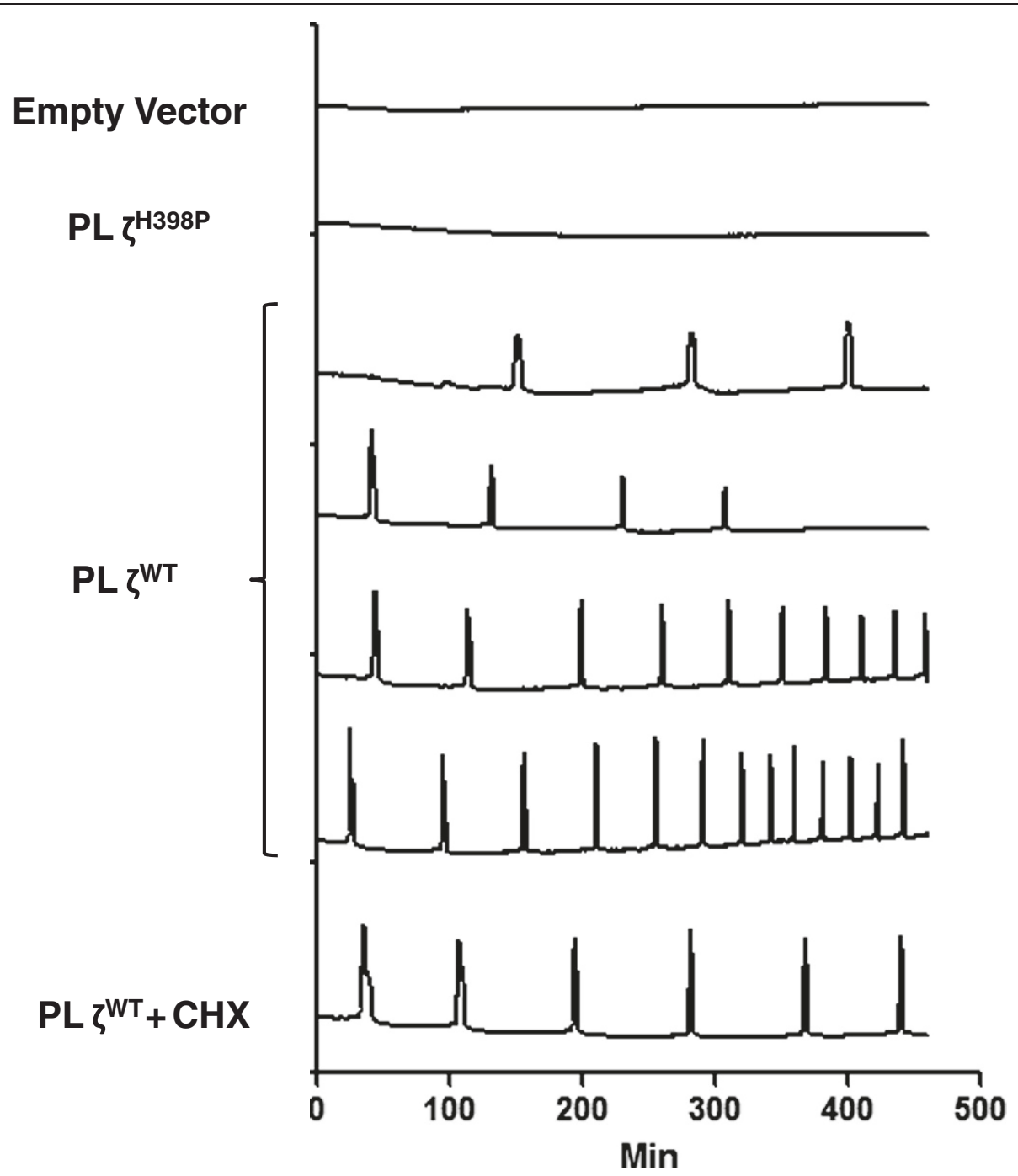

Figure 9 Representative $\mathrm{Ca}^{2+}$ oscillation profiles of mouse oocytes injected with lysates obtained from HEK293T cells transfected with PLCל isoforms. Baseline values for all $\mathrm{Ca}^{2+}$ traces are stacked to facilitate visualization of the responses. Empty vector: $\mathrm{Ca}^{2+}$ trace obtained from injection of lysates obtained from HEK293T cells transfected with vector without PLC $;$ PLCC ${ }^{\mathrm{H} 398 \mathrm{P}}$ : $\mathrm{Ca}^{2+}$ trace obtained from injection of lysates

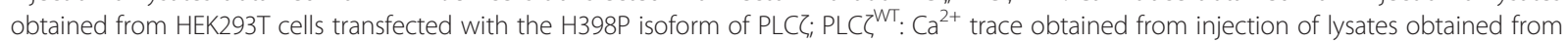
HEK293T cells transfected with wild type PLCZ; CHX: cyclohexamide (an inhibitor of RNA synthesis). Figure reproduced from Kashir et al. (2011a) with permission.

the activation capacity of human sperm by microinjection into mouse oocytes $[3,134,136]$. This assay represents a useful method with which to investigate cases of low ICSI success rates [106]. However, considering that human PLCC is thought to be more potent in its activity compared to mouse PLCל [33], and that oocytes from various species are thought to be 'fine-tuned' to specific levels and activity of PLCC from that species [64], it is possible that the MOAT may only be useful to detect extreme cases of OAD where sperm is completely devoid of PLC $\zeta$, and not cases where only a more subtle reduction is evident. Of course, such tests require the provision of animal facilities and specialised skills which may not be routinely available for most ART centres, and may therefore be more useful in a research setting.

Identifying a pattern of localisation of PLC $\zeta$ that is compatible with its role as the putative endogenous oocyte activation factor provides further confirmation of its physiological relevance as a mediator of this important process. Moreover, the identification of specific localisation patterns in fertile males, and their precise functional roles, would provide a key benchmark to which infertile sperm may be compared. Previous work using immunofluorescent techniques has already demonstrated that there appears to be a pattern of PLC $\zeta$ localisation in the sperm head that is consistent with fertile sperm $[86,106]$, 
and an abnormal pattern evident in ICSI-failed sperm [74,86,107], implicating a correlation between an abnormal localisation pattern of PLC $\zeta$ with aberrant function/ infertility. This suggests that by determining the expression, and localisation pattern, of PLC $\zeta$ in sperm is likely to represent a credible index of oocyte activation ability for patients seeking ART.

Kashir et al. (2011b) investigated the effects of routine ART techniques upon the levels of PLC $\zeta$ in fertile male donors, and revealed that cryopreservation, a common technique utilised for the preservation of fertility in patients undergoing fertility treatment as well as radio/ chemotherapy or surgery [151], had a significant detrimental effect upon the levels of PLC $\zeta$ compared with fresh sperm [152]. Furthermore, Nakai et al. (2011) showed that the pre-treatment of pig sperm reduced oocyte-activating ability via significant reductions in the levels of PLC $\zeta$ levels compared with untreated sperm [110]. Interestingly, Nakai et al. (2011) also detected a population of PLCC in the tail of pig sperm. Removal of the tail via pre-treatment methods reduced oocyte-activation ability, indicating that optimal ability was achieved via ICSI using only whole sperm [110]. Given that low PLCל concentrations in sperm are linked with infertility, these studies further support the notion that PLC $\zeta$ represents a beneficial biomarker for ART. Indeed, Kashir et al. (2011b) demonstrated that density gradient washing (DGW; a centrifugation method used to isolate the best quality sperm based on motility parameters) increased the proportion of sperm exhibiting PLCC immunofluorescence in fertile male donors [152], thus increasing the likelihood of successful activation.

Since PLC $\zeta$ mRNA has been identified in sperm $[120,121]$, it is possible that the determination of PLC $\zeta$ mRNA may represent another useful clinical indicator, although the precise function of this mRNA store is not yet known. Several studies have already demonstrated the differential expression of some key mRNAs in infertile males compared to fertile males [122,147,153], thus suggesting the potential for the development of a fertility index via relative expression analysis. Indeed, Kaewmala et al. (2011) indicated that higher levels of PLCᄃ mRNA in boar sperm correlated with better quality [109], while Aghajanpour et al. (2011) investigated whether the level of PLC $\zeta$ mRNA in human sperm may be an indicator of the potential of a patient sample to induce oocyte activation [115]. The authors of the latter report identified a significant reduction in levels of PLC $\zeta$ mRNA in individuals with low or failed fertilisation with ICSI, compared to fertile controls. It follows then that the relative expression of PLC $\zeta$ mRNA may represent a credible biomarker of the oocyte activation ability of a given sperm sample. Indeed, several authors hypothesise that the future of male infertility diagnosis may rely heavily upon the use of microarrays to determine the expression levels of target mRNAs in discrete sperm samples [154-158].

Interestingly, a recent study revealed that by assessing the rhythmical cytoplasmic movements triggered by $\mathrm{Ca}^{2+}$ oscillations in the fertilised mouse oocyte using particle image velocimetry (PIV), it was possible to predict the developmental potential of the zygote [159], thus offering a potential viability index for oocytes fertilised in-vitro. Swann et al. (2012) further validated the concept of PIV analysis by demonstrating that the frequency of PLC $\zeta-$ induced cytoplasmic $\mathrm{Ca}^{2+}$ oscillations and the pattern of cytoplasmic movements within aged ICSI-failed human oocytes were synchronous in nature [160]. Collectively, these studies indicate that the use of PIV to analyse cytoplasmic movements may represent an exciting non-invasive method for monitoring $\mathrm{Ca}^{2+}$ oscillation patterns in human oocytes in a clinical setting, thereby providing an early and effective indicator of zygote viability following IVF $[159,160]$.

Increasing evidence supports the importance of oocyte factors in the fertilising potential of an oocyte. The oocyte undergoes cellular arrangement and modifications during maturation to optimise the internal environment for optimal $\mathrm{Ca}^{2+}$ release ability upon sperm fusion [128]. A dysfunctional environment within the oocyte, in the case of an aged oocyte for example, is very likely to impede the process of fertilisation [161]. Further understanding of the factors and mechanisms involved in creating a fully viable oocyte are equally as important as understanding the manner in which the fertilising sperm induces $\mathrm{Ca}^{2+}$ release upon gamete fusion. Important lessons can be gained via expression studies in the laboratory; for example, studies demonstrating successful $\mathrm{Ca}^{2+}$ release upon the expression of recombinant PLCC in one specific cell line but not another cell type [74,93], indicate that there may be hitherto unknown oocyte components that are required for the activation process. Elucidation of the specific identities of such factors may explain how PLCC is maintained in an inactive state in the sperm but activated upon release into the oocyte. Furthermore, evidence suggests that in addition to interaction with oocyte factors, PLC $\zeta$ may undergo posttranslational modifications before attaining the ability to induce $\mathrm{Ca}^{2+}$ release. Cooney et al. (2010) suggest that this is a key requirement for PLC $\zeta$ to attain endogenous activity $[64,74,162]$. It is important that future studies aim to confirm whether post-translational modifications and/or proteolytic cleavage, are important for the functional role of PLC $\zeta$, and address how deficiencies in these processes may relate to an infertile state.

\section{Conclusions}

It is clear that PLC $\zeta$ plays a fundamental role in the activation of mammalian oocytes and that genetic, molecular or 
biochemical perturbation of this key protein is strongly linked to OAD and human infertility. Consequently, there is significant scope for our understanding of PLCל to be translated to the ART clinic, both as a novel therapeutic agent with which to rescue OAD, or as a prognostic/ diagnostic biomarker of oocyte activation ability in target sperm samples. However, there are several key target areas for future research that must be addressed. Firstly, al-

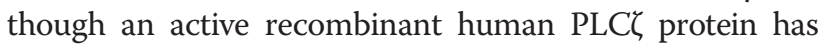
been successfully synthesised in mammalian cell lysates [74], steps must now be taken to extend such progress to final purification, concentration, and activity testing. Such work underpins the successful deployment of recombinant PLC $\zeta$ protein as a more physiological method of AOA compared to current protocols. Secondly, there is significant interest at present to identify novel biomarkers of sperm function to complement and extend current semen analysis procedures in the ART clinic. Initial findings indi-

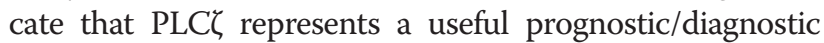
biomarker of oocyte activation ability. However, several questions remain to be addressed before PLC $\zeta$ may be competently utilised in this clinical capacity. For example, we cannot yet confirm beyond doubt whether a specific pattern of PLCל localisation is required for successful oocyte activation, or whether the mere presence of PLC $\zeta$ within a particular concentration window, regardless of localisation pattern, is all that is required. It is also necessary to address the potential effects that routine ART laboratory techniques may exert upon PLC $\zeta$ concentration and function within human sperm, and whether such effects may inadvertently reduce fertilisation capacity in a clinical setting. It is imperative that future research adopts a range of experimental approaches in the research laboratory, but also allows for intensified screening within the clinical setting, which includes cases related to OAD, ICSI-failure, and idiopathic infertility. It is readily apparent that clinical data relating to PLC $\zeta$ is still lacking, and that our current understanding is based on only a limited number of cases. However, given appropriate levels of research attention, it is already clear that PLC $\zeta$ is likely to provide the ART clinic with significant improvements to prognostic and diagnostic testing, and safer options for therapeutic intervention.

\footnotetext{
Abbreviations

WHO: World Health Organisation; ART: Assisted reproductive technology; HFEA: Human Fertilisation and Embryology Authority; IVF: In-vitro fertilisation; ICSI: Intracytoplasmic sperm injection; CG: Cortical granule; PN: Pro-nuclear; $\mathrm{Ca}^{2+}$ : Calcium; $\mathrm{IP}_{3}$ : Inositol trisphosphate; ER: Endoplasmic reticulum; PLC: Phospholipase C; PIP 2 : Phosphotidylinositol 4,5-bisphosphate; DAG: Diacylglycerol; PKC: Protein kinase C; PAWP: Post-acrosomal sheath WW domain-binding protein; NLS: Nuclear localisation signal; OAD: Oocyte activation deficiency; AOA: Artificial oocyte activation; MOAT: Mouse oocyte activation test; PIV: Particle image velocimetry.
}

\section{Competing interests}

The authors declare that they have no competing interests.

\section{Acknowledgements}

Some research described herein was funded by project grants from the Royal Society (UK) and the Oxford University Medical Research Fund awarded to KC. WRM is funded by a Departmental Studentship (Nuffield Department of Obstetrics \& Gynaecology, University of Oxford) and the Medical Research Council (U.K.)

\section{Authors' contribution}

WMR, JK, CJ, and KC all contributed to the writing of this manuscript. All authors read and approved the final version of this manuscript.

Received: 6 March 2012 Accepted: 16 May 2012

Published: 16 May 2012

\section{References}

1. Boivin J, Bunting L, Collins JA, Nygren KG: International estimates of infertility prevalence and treatment-seeking: potential need and demand for infertility medical care. Hum Reprod 2007, 22(6):1506-1512.

2. Ombelet W, Cooke I, Dyer S, Serour G, Devroey P: Infertility and the provision of infertility medical services in developing countries. Hum Reprod Update 2008, 14(6):605-621.

3. Kashir J, Heindryckx B, Jones C, De Sutter P, Parrington J, Coward K: Oocyte activation, phospholipase $C$ zeta and human infertility. Hum Reprod Update 2010, 16(6):690-703.

4. Zegers-Hochschild F, Adamson GD, de Mouzon J, Ishihara O, Mansour R, Nygren K, Sullivan E, van der Poel S: The International Committee for Monitoring Assisted Reproductive Technology (ICMART) and the World Health Organization (WHO) revised glossary on ART terminology, 2009. Hum Reprod 2009, 24(11):2683-2687.

5. HFEA: Latest UK IVF figures-2009 and 2010. [http://www.hfea.gov.uk/ivffigures-2006.html].

6. Nasr-Esfahani MH, Deemeh MR, Tavalaee M: Artificial oocyte activation and intracytoplasmic sperm injection. Fertil Steril 2010, 94(2):520-526.

7. Wilkes S, Chinn DJ, Murdoch A, Rubin G: Epidemiology and management of infertility: a population-based study in UK primary care. Fam Pract 2009, 26(4):269-274.

8. Palermo G, Joris H, Devroey P, Van Steirteghem AC: Pregnancies after intracytoplasmic injection of single spermatozoon into an oocyte. Lancet 1992, 340(8810):17-18.

9. Yanagida K, Fujikura Y, Katayose $\mathrm{H}$ : The present status of artificial oocyte activation in assisted reproductive technology. Reprod Med Biol 2008, 7 (3):133-142

10. de Mouzon J, Goossens V, Bhattacharya S, Castilla JA, Ferraretti AP, Korsak V, Kupka M, Nygren KG, Nyboe Andersen A: Assisted reproductive technology in Europe, 2007: results generated from European registers by ESHRE. Hum Reprod 2012, 27(4):954-966.

11. Jones KT, Carroll J, Merriman JA, Whittingham DG, Kono T: Repetitive sperm-induced $\mathrm{Ca}^{2+}$ transients in mouse oocytes are cell cycle dependent. Development 1995, 121(10):3259-3266.

12. Horner $\mathrm{VL}$, Wolfner MF: Transitioning from egg to embryo: Triggers and mechanisms of egg activation. Dev Dyn 2008, 237(3):527-544.

13. Dale B, Wilding M, Coppola GF, Tosti E: How do spermatozoa activate oocytes? Reprod Biomed Online 2010, 21(1):1-3.

14. Kline D, Kline JT: Repetitive calcium transients and the role of calcium in exocytosis and cell cycle activation in the mouse egg. Developmental Biology 1992, 149(1):80-89.

15. Stricker SA: Comparative biology of calcium signaling during fertilization and egg activation in animals. Dev Biol 1999, 211(2):157-176.

16. Ducibella T, Huneau D, Angelichio E, Xu Z, Schultz RM, Kopf GS, Fissore R, Madoux S, Ozil J-P: Egg-to-embryo transition is driven by differential responses to $\mathrm{Ca}^{2+}$ oscillation number. Dev Biol 2002, 250(2):280-291.

17. Ducibella T, Schultz RM, Ozil J-P: Role of calcium signals in early development. Semin Cell Dev Biol 2006, 17(2):324-332.

18. Malcuit C, Kurokawa M, Fissore RA: Calcium oscillations and mammalian egg activation. J Cell Physiol 2006, 206(3):565-573.

19. Miyazaki S, Ito M: Calcium signals for egg activation in mammals. J Pharmacol Sci 2006, 100(5):545-552.

20. Liu M: The biology and dynamics of mammalian cortical granules. Reprod Biol Endocrinol 2011, 9(1):149.

21. Miyazaki S: Thirty years of calcium signals at fertilization. Semin Cell Dev Biol 2006, 17(2):233-243. 
22. Publicover $\mathrm{S}$, Harper $\mathrm{CV}$, Barratt $\mathrm{C}:\left[\mathrm{Ca}^{2+}\right]_{i}$ signalling in sperm - making the most of what you've got. Nat Cell Biol 2007, 9(3):235-242.

23. Swann $K, Y u$ Y: The dynamics of calcium oscillations that activate mammalian eggs. Int J Dev Biol 2008, 52(5-6):585-94.

24. White $K L$, Pate $B J$, Sessions BR: Oolemma receptors and oocyte activation. Syst Biol Reprod Med 2010, 56(5):365-375.

25. Fulton BP, Whittingham DG: Activation of mammalian oocytes by intracellular injection of calcium. Nature 1978, 273(5658):149-151.

26. Jones KT, Soeller C, Cannell MB: The passage of $\mathrm{Ca}^{2+}$ and fluorescent markers between the sperm and egg after fusion in the mouse. Development 1998, 125(23):4627-4635.

27. Miyazaki S, Yuzaki M, Nakada K, Shirakawa H, Nakanishi S, Nakade S, Mikoshiba K: Block of $\mathrm{Ca}^{2+}$ wave and $\mathrm{Ca}^{2+}$ oscillation by antibody to the inositol 1,4,5-trisphosphate receptor in fertilized hamster eggs. Science 1992, 257(5067):251-255.

28. Fissore RA, Longo FJ, Anderson E, Parys JB, Ducibella T: Differential distribution of inositol trisphosphate receptor isoforms in mouse oocytes. Biol Reprod 1999, 60(1):49-57.

29. Kurokawa M, Sato K-i, Fissore RA: Mammalian fertilization: from sperm factor to phospholipase Czeta. Biol Cell 2004, 96(1):37-45.

30. Malcuit C, Knott JG, He C, Wainwright T, Parys JB, Robl JM, Fissore RA: Fertilization and inositol 1,4,5-trisphosphate $\left(\mathrm{IP}_{3}\right)$-induced calcium release in type-1 inositol 1,4,5-trisphosphate receptor down-regulated bovine eggs. Biol Reprod 2005, 73(1):2-13.

31. Lee B, Yoon S-Y, Fissore RA: Regulation of fertilization-initiated $\left[\mathrm{Ca}^{2+}\right]_{\mathrm{i}}$ oscillations in mammalian eggs: A multi-pronged approach. Semin Cell Dev Biol 2006, 17(2):274-284.

32. Oda S: Mammalian sperm factor and phospholipase $C$ zeta. J Mammalian Ova Res 2006, 23(1):2-9.

33. Swann K, Saunders CM, Rogers NT, Lai FA: PLCZ (zeta): A sperm protein that triggers $\mathrm{Ca}^{2+}$ oscillations and egg activation in mammals. Sem Cell Dev Biol 2006, 17(2):264-273.

34. Whitaker M: Calcium at fertilization and in early development. Physiol Rev 2006, 86(1):25-88.

35. Parrington J, Davis LC, Galione A, Wessel G: Flipping the switch: How a sperm activates the egg at fertilization. Dev Dyn 2007, 236(8):2027-2038.

36. Saunders CM, Swann K, Lai FA: PLCzeta, a sperm-specific PLC and its potential role in fertilization. Biochem Soc Symp 2007, 74:23-36.

37. Berridge MJ: Inositol trisphosphate and calcium signalling mechanisms. Biochim Biophys Acta 2009, 1793(6):933-940.

38. Parrington J: Does a soluble sperm factor trigger calcium release in the egg at fertilization? J Androl 2001, 22(1):1-11.

39. Miyazaki $\mathrm{S}$, Shirakawa H, Nakada K, Honda Y: Essential role of the inositol 1,4,5-trisphosphate receptor/Ca ${ }^{2+}$ release channel in $\mathrm{Ca}^{2+}$ waves and $\mathrm{Ca}^{2+}$ oscillations at fertilization of mammalian eggs. Dev Biol 1993, 158(1):62-78.

40. Brind S, Swann K, Carroll J: Inositol 1,4,5-trisphosphate receptors are downregulated in mouse oocytes in response to sperm or adenophostin A but not to increases in intracellular $\mathrm{Ca}^{2+}$ or egg activation. Dev Biol 2000, 223(2):251-265.

41. Jellerette $T, \mathrm{He} C L$, Wu H, Parys JB, Fissore RA: Down-regulation of the inositol 1,4,5-trisphosphate receptor in mouse eggs following fertilization or parthenogenetic activation. Dev Biol 2000, 223(2):238-250.

42. Xu Z, Williams CJ, Kopf GS, Schultz RM: Maturation-associated increase in $\mathrm{IP}_{3}$ receptor type 1: role in conferring increased $\mathrm{IP}_{3}$ sensitivity and $\mathrm{Ca}^{2+}$ oscillatory behavior in mouse eggs. Dev Biol 2003, 254(2):163-171.

43. Fissore RA, Dobrinsky JR, Balise JJ, Duby RT, Robl JM: Patterns of intracellular $\mathrm{Ca}^{2+}$ concentrations in fertilized bovine eggs. Biol Reprod 1992, 47(6):960-969.

44. Ozil J-P: Role of calcium oscillations in mammalian egg activation: experimental approach. Biophys Chem 1998, 72(1-2):141-152.

45. Ozil J-P, Banrezes B, Toth S, Pan H, Schultz RM: $\mathrm{Ca}^{2+}$ oscillatory pattern in fertilized mouse eggs affects gene expression and development to term. Dev Biol 2006, 300(2):534-544.

46. Jones KT: Intracellular calcium in the fertilisation and development of mammalian eggs. Clin Exp Pharmacol Physiol 2007, 34(10):1084-1089.

47. Boulware MJ, Marchant JS: Timing in cellular $\mathrm{Ca}^{2+}$ signaling. Curr Biol 2008, 18(17):R769-R776.

48. Swann K, Ozil J-P: Dynamics of the calcium signal that triggers mammalian egg activation. Int Rev Cytol 1994, 152:183-222.

49. Wong CC, Loewke KE, Bossert NL, Behr B, De Jonge CJ, Baer TM, Pera RAR: Non-invasive imaging of human embryos before embryonic genome activation predicts development to the blastocyst stage. Nat Biotechnol 2010, 28(10):1115-1121.

50. Kim B, Yoon S-Y, Cha S, Kwak K, Fissore R, Parys J, Yoon T, Lee D: Alterations in calcium oscillatory activity in vitrified mouse eggs impact on egg quality and subsequent embryonic development. Pflügers Arch 2011, 461(5):515-526.

51. Nomikos M, Swann K, Lai FA: Starting a new life: Sperm PLC-zeta mobilizes the $\mathrm{Ca}^{2+}$ signal that induces egg activation and embryo development. BioEssays 2011, 34(2):126-134

52. Jaffe LA: First messengers at fertilization. J Reprod Fertil Supp/ 1990 42:107-116.

53. Swann K: A cytosolic sperm factor stimulates repetitive calcium increases and mimics fertilization in hamster eggs. Development 1990, 110(4):1295-1302.

54. Kyozuka K, Deguchi R, Mohri T, Miyazaki S: Injection of sperm extract mimics spatiotemporal dynamics of $\mathrm{Ca}^{2+}$ responses and progression of meiosis at fertilization of ascidian oocytes. Development 1998, 125 (20):4099-4105.

55. Dong J-B, Tang T-S, Sun F-Z: Xenopus and chicken sperm contain a cytosolic soluble protein factor which can trigger calcium oscillations in mouse eggs. Biochem Biophys Res Commun 2000, 268(3):947-951.

56. Coward K, Campos-Mendoza A, Larman M, Hibbitt O, McAndrew B, Bromage N, Parrington J: Teleost fish spermatozoa contain a cytosolic protein factor that induces calcium release in sea urchin egg homogenates and triggers calcium oscillations when injected into mouse oocytes. Biochem Biophys Res Commun 2003, 305(2):299-304.

57. Coward $K$, Ponting $C P$, Chang H-Y, Hibbitt $O$, Savolainen $P$, Jones $K T$, Parrington J: Phospholipase $C \zeta$, the trigger of egg activation in mammals, is present in a non-mammalian species. Reproduction 2005, 130(2):157-163.

58. Tesarik J, Testart J: Treatment of sperm-injected human oocytes with $\mathrm{Ca}^{2+}$ ionophore supports the development of $\mathrm{Ca}^{2+}$ oscillations. Biol Reprod 1994, 51(3):385-391.

59. Saunders CM, Larman MG, Parrington J, Cox LJ, Royse J, Blayney LM, Swann K, Lai FA: PLCC: a sperm-specific trigger of $\mathrm{Ca}^{2+}$ oscillations in eggs and embryo development. Development 2002, 129(15):3533-3544.

60. Wu H, He CL, Fissore RA: Injection of a porcine sperm factor triggers calcium oscillations in mouse oocytes and bovine eggs. Mol Reprod Dev 1997, 46(2):176-189.

61. Cox L, Larman MG, Saunders CM, Hashimoto K, Swann K, Lai FA: Sperm phospholipase Czeta from humans and cynomolgus monkeys triggers $\mathrm{Ca}^{2+}$ oscillations, activation and development of mouse oocytes. Reproduction 2002, 124(5):611-623.

62. Yoneda A, Kashima M, Yoshida S, Terada K, Nakagawa S, Sakamoto A, Hayakawa K, Suzuki K, Ueda J, Watanabe T: Molecular cloning, testicular postnatal expression, and oocyte-activating potential of porcine phospholipase CC. Reproduction 2006, 132(3):393-401.

63. Young C, Grasa P, Coward K, Davis CL, Parrington J: Phospholipase C zeta undergoes dynamic changes in its pattern of localization in sperm during capacitation and the acrosome reaction. Fertil Steril 2009, 91 (5):2230-2242.

64. Cooney MA, Malcuit C, Cheon B, Holland MK, Fissore RA, D'Cruz NT: Speciesspecific differences in the activity and nuclear localization of murine and bovine phospholipase C zeta 1. Biol Reprod 2010, 83(1):92-101.

65. Bedford-Guaus SJ, McPartlin LA, Xie J, Westmiller SL, Buffone MG, Roberson MS: Molecular cloning and characterization of phospholipase $C$ zeta in equine sperm and testis reveals species-specific differences in expression of catalytically active protein. Biol Reprod 2011, 85(1):78-88.

66. Ito M, Shikano T, Kuroda K, Miyazaki S: Relationship between nuclear sequestration of $\mathrm{PLC}$ and termination of $\mathrm{PLC}$-induced $\mathrm{Ca}^{2+}$ oscillations in mouse eggs. Cell Calcium 2008, 44(4):400-410.

67. Mizushima S, Takagi S, Ono T, Atsumi Y, Tsukada A, Saito N, Shimada K Phospholipase $C \zeta$ mRNA expression and its potency during spermatogenesis for activation of quail oocyte as a sperm factor. $\mathrm{Mol}$ Reprod Dev 2009, 76(12):1200-1207.

68. Coward K, Ponting CP, Zhang N, Young C, Huang C-J, Chou C-M, Kashir J, Fissore RA, Parrington J: Identification and functional analysis of an ovarian form of the egg activation factor phospholipase C zeta (PLCC) in pufferfish. Mol Reprod Dev 2011, 78(1):48-56.

69. Kouchi Z, Fukami K, Shikano T, Oda S, Nakamura Y, Takenawa T, Miyazaki S: Recombinant phospholipase $\mathrm{C} \zeta$ has high $\mathrm{Ca}^{2+}$ sensitivity and induces $\mathrm{Ca}^{2+}$ oscillations in mouse eggs. J Biol Chem 2004, 279 (11):10408-10412 
70. Campbell $\mathrm{K}$, Swann $\mathrm{K}: \mathrm{Ca}^{2+}$ oscillations stimulate an ATP increase during fertilization of mouse eggs. Dev Biol 2006, 298(1):225-233.

71. Yu Y, Saunders CM, Lai FA, Swann K: Preimplantation development of mouse oocytes activated by different levels of human phospholipase $C$ zeta. Hum Reprod 2008, 23(2):365-373.

72. Ross $\mathrm{P}$, Beyhan Z, lager A, Yoon S-Y, Malcuit C, Schellander K, Fissore R, Cibelli J: Parthenogenetic activation of bovine oocytes using bovine and murine phospholipase C zeta. BMC Dev Biol 2008, 8(1):16-27.

73. Ross PJ, Rodriguez RM, lager AE, Beyhan Z, Wang K, Ragina NP, Yoon S-Y, Fissore RA, Cibelli JB: Activation of bovine somatic cell nuclear transfer embryos by PLCZ cRNA injection. Reproduction 2009, 137(3):427-437.

74. Kashir J, Jones C, Lee HC, Rietdorf K, Nikiforaki D, Durrans C, Ruas M, Tee ST, Heindryckx B, Galione A, De Sutter P, Fissore RA, Parrington J, Coward K: Loss of activity mutations in phospholipase C zeta (PLC) abolishes calcium oscillatory ability of human recombinant protein in mouse oocytes. Hum Reprod 2011, 26(12):3372-3387.

75. Rogers NT, Hobson E, Pickering S, Lai FA, Braude P, Swann K: Phospholipase $\mathrm{Cl}$ causes $\mathrm{Ca}^{2+}$ oscillations and parthenogenetic activation of human oocytes. Reproduction 2004, 128(6):697-702.

76. Knott JG, Kurokawa M, Fissore RA, Schultz RM, Williams CJ: Transgenic RNA interference reveals role for mouse sperm phospholipase $C \zeta$ in triggering $\mathrm{Ca}^{2+}$ oscillations during fertilization. Biol Reprod 2005, 72(4):992-996.

77. Yoshida N, Amanai M, Fukui T, Kajikawa E, Brahmajosyula M, Iwahori A, Nakano Y, Shoji S, Diebold J, Hessel H, Huss R, Perry ACF: Broad, ectopic expression of the sperm protein PLCZ1 induces parthenogenesis and ovarian tumours in mice. Development 2007, 134(21):3941-3952.

78. Evans JP, Kopf GS: Molecular mechanisms of sperm-egg interactions and egg activation. Andrologia 1998, 30(4-5):297-307.

79. Sette C, Bevilacqua A, Bianchini A, Mangia F, Geremia R, Rossi P: Parthenogenetic activation of mouse eggs by microinjection of a truncated c-kit tyrosine kinase present in spermatozoa. Development 1997, 124(11):2267-2274.

80. Harada Y, Matsumoto T, Hirahara S, Nakashima A, Ueno S, Oda S, Miyazaki S, Iwao $Y$ : Characterization of a sperm factor for egg activation at fertilization of the newt Cynops pyrrhogaster. Dev Biol 2007, 306(2):797-808.

81. Wu ATH, Sutovsky P, Manandhar G, Xu W, Katayama M, Day BN, Park K-W, Yi Y-J, Xi YW, Prather RS, Oko R: PAWP, a Sperm-specific WW domain-binding protein, promotes meiotic resumption and pronuclear development during fertilization. J Biol Chem 2007, 282(16):12164-12175.

82. Aarabi M, Qin Z, Xu W, Mewburn J, Oko R: Sperm-borne protein, PAWP, initiates zygotic development in Xenopus laevis by eliciting intracellular calcium release. Mol Reprod Dev 2010, 77(3):249-256.

83. Williams RL: Mammalian phosphoinositide-specific phospholipase C. Biochim Biophys Acta 1999, 1441(2-3):255-267.

84. Rebecchi MJ, Pentyala SN: Structure, function, and control of phosphoinositide-specific phospholipase C. Physiol Rev 2000, 80(4):1291-1335.

85. Suh PG, Park JI, Manzoli L, Cocco L, Peak JC, Katan M, Fukami K, Kataoka T, Yun S, Ryu SH: Multiple roles of phosphoinositide-specific phospholipase C isozymes. BMB Rep 2008, 41(6):415-434.

86. Heytens E, Parrington J, Coward K, Young C, Lambrecht S, Yoon S-Y, Fissore RA, Hamer R, Deane CM, Ruas M, Grasa P, Soleimani R, Cuvelier CA, Gerris J, Dhont M, Deforce D, Leybaert L, De Sutter P: Reduced amounts and abnormal forms of phospholipase C zeta (PLC) in spermatozoa from infertile men. Hum Reprod 2009, 24(10):2417-2428.

87. Nomikos M, Elgmati K, Theodoridou M, Calver BL, Nounesis G, Swann K, Lai FA: Phospholipase $C \zeta$ binding to $\operatorname{Ptd} \ln (4,5) \mathrm{P}_{2}$ requires the $\mathrm{XY}$-linker region. J Cell Sci 2011, 124(15):2582-2590.

88. Nomikos M, Elgmati K, Theodoridou M, Calver BL, Cumbes B, Nounesis G, Swann K, Lai FA: Male infertility-linked point mutation disrupts the $\mathrm{Ca}^{2+}$ oscillation-inducing and $\mathrm{PIP}_{2}$ hydrolysis activity of sperm PLCC. Biochem J 2011, 434(2):211-217.

89. Kurokawa M, Yoon SY, Alfandari D, Fukami K, Sato K-i, Fissore RA: Proteolytic processing of phospholipase $\mathrm{C} \zeta$ and $\left[\mathrm{Ca}^{2+}\right]_{\mathrm{i}}$ oscillations during mammalian fertilization. Dev Biol 2007, 312(1):407-418.

90. Nomikos M, Mulgrew-Nesbitt A, Pallavi P, Mihalyne G, Zaitseva I, Swann K, Lai FA, Murray D, McLaughlin S: Binding of phosphoinositide-specific

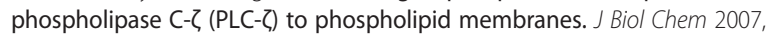
282(22):16644-16653.

91. Nomikos M, Elgmati K, Theodoridou M, Georgilis A, Gonzalez-Garcia JR, Nounesis G, Swann K, Lai FA: Novel regulation of PLCZ activity via its XYlinker. Biochem J 2011, 438(3):427-432.
92. Yu Y, Nomikos M, Theodoridou M, Nounesis G, Lai FA, Swann K: PLC(zeta)\} causes $\mathrm{Ca}^{2+}$ oscillations in mouse eggs by targeting intracellular and not plasma membrane PI(4,5) $\mathrm{P}_{2}$. Mol Biol Cell 2011, 23(2):371-380.

93. Phillips SV, Yu Y, Rossbach A, Nomikos M, Vassilakopoulou V, Livaniou E, Cumbes B, Lai FA, George CH, Swann K: Divergent effect of mammalian $\mathrm{PLC}$ in generating $\mathrm{Ca}^{2+}$ oscillations in somatic cells compared with eggs. Biochem J 2011, 438(3):545-553.

94. Marangos P, FitzHarris G, Carroll J: $\mathrm{Ca}^{2+}$ oscillations at fertilization in mammals are regulated by the formation of pronuclei. Development 2003, 130(7):1461-1472.

95. Larman MG, Saunders CM, Carroll J, Lai FA, Swann K: Cell cycle-dependent $\mathrm{Ca}^{2+}$ oscillations in mouse embryos are regulated by nuclear targeting of PLCZ. J Cell Sci 2004, 117(12):2513-2521.

96. Yoda A, Oda S, Shikano T, Kouchi Z, Awaji T, Shirakawa H, Kinoshita K, Miyazaki S: $\mathrm{Ca}^{2+}$ oscillation-inducing phospholipase $\mathrm{C}$ zeta expressed in mouse eggs is accumulated to the pronucleus during egg activation. Dev Biol 2004, 268(2):245-257.

97. Ito M, Shikano T, Oda S, Horiguchi T, Tanimoto S, Awaji T, Mitani H, Miyazaki S: Difference in $\mathrm{Ca}^{2+}$ Oscillation-Inducing Activity and Nuclear Translocation Ability of PLCZ1, an Egg-Activating Sperm Factor Candidate, Between Mouse, Rat, Human, and Medaka Fish. Biol Reprod 2008, 78(6):1081-1090.

98. Kuroda K, Ito M, Shikano T, Awaji T, Yoda A, Takeuchi H, Kinoshita K, Miyazaki S: The role of $\mathrm{X} / \mathrm{Y}$ linker region and N-terminal EF-hand domain in nuclear translocation and $\mathrm{Ca}^{2+}$ oscillation-inducing activities of phospholipase Cद, a mammalian egg-activating factor. J Biol Chem 2006, 281(38):27794-27805.

99. Kouchi Z, Shikano T, Nakamura Y, Shirakawa H, Fukami K, Miyazaki S: The role of EF-hand domains and C2 domain in regulation of enzymatic activity of phospholipase CZ.J Biol Chem 2005, 280(22):21015-21021.

100. Nakanishi T, Ishibashi N, Kubota H, Inoue K, Ogonuki N, Ogura A, Kashiwabara S-i, Baba T: Birth of normal offspring from mouse eggs activated by a phospholipase $\mathrm{C}$ zeta; protein lacking three EF-hand domains. J Reprod Dev 2008, 54(4):244-249.

101. Coward K, Kubota H, Hibbitt O, Mcllinney J, Kohri K, Parrington J: Expression of a fluorescent recombinant form of sperm protein phospholipase $C$ zeta in mouse epididymal sperm by in vivo gene transfer into the testis. Fertil Steril 2006, 85:1281-1289. Supplement 1(0).

102. Yoon S-Y, Fissore RA: Release of phospholipase $\mathrm{C} \zeta$ and $\left[\mathrm{Ca}^{2+}\right]_{\mathrm{i}}$ oscillationinducing activity during mammalian fertilization. Reproduction 2007, 134 (5):695-704.

103. Sone Y, Ito M, Shirakawa H, Shikano T, Takeuchi H, Kinoshita K, Miyazaki S: Nuclear translocation of phospholipase C-zeta, an egg-activating factor, during early embryonic development. Biochem Biophys Res Commun 2005, 330(3):690-694.

104. Kurokawa M, Sato K-i, Wu H, He C, Malcuit C, Black SJ, Fukami K, Fissore RA: Functional, biochemical, and chromatographic characterization of the complete $\left[\mathrm{Ca}^{2+}\right]_{\mathrm{i}}$ oscillation-inducing activity of porcine sperm. Dev Biol 2005, 285(2):376-392.

105. Nomikos M, Blayney LM, Larman MG, Campbell K, Rossbach A, Saunders CM, Swann K, Lai K: Role of phospholipase C- domains in $\mathrm{Ca}^{2+}$-dependent phosphatidylinositol 4,5-bisphosphate hydrolysis and cytoplasmic $\mathrm{Ca}^{2+}$ oscillations. J Biol Chem 2005, 280(35):31011-31018.

106. Grasa P, Coward K, Young C, Parrington J: The pattern of localization of the putative oocyte activation factor, phospholipase $C \zeta$, in uncapacitated, capacitated, and ionophore-treated human spermatozoa. Hum Reprod 2008, 23(11):2513-2522.

107. Yoon S-Y, Jellerette T, Salicioni AM, Lee HC, Yoo M-S, Coward K, Parrington J, Grow D, Cibelli JB, Visconti PE, Mager J, Fissore RA: Human sperm devoid of PLC, zeta 1 fail to induce $\mathrm{Ca}^{2+}$ release and are unable to initiate the first step of embryo development. J Clin Invest 2008, 118(11):3671-3681.

108. Fujimoto S, Yoshida N, Fukui T, Amanai M, Isobe T, Itagaki C, Izumi T, Perry ACF: Mammalian phospholipase $C \zeta$ induces oocyte activation from the sperm perinuclear matrix. Dev Biol 2004, 274(2):370-383.

109. Kaewmala K, Uddin MJ, Cinar MU, Große-Brinhaus C, Jonas E, Tesfaye D, Phatsara C, Tholen E, Looft C, Schellander K: Investigation into association and expression of PLCZ and COX-2 as candidate genes for boar sperm quality and fertility. Reprod Domest Anim 2012, 47(2):213-223.

110. Nakai M, Ito J, Sato K-i, Noguchi J, Kaneko H, Kashiwazaki N, Kikuchi K: Pre-treatment of sperm reduces success of ICSI in the pig. Reproduction 2011, 142(2):285-293. 
111. Bi Y, Xu W-M, Wong HY, Zhu H, Zhou Z-M, Chan HC, Sha J-H: NYD-SP27, a novel intrinsic decapacitation factor in sperm. Asian J Androl 2009, 11 (2):229-239.

112. Lawrence $Y$, Whitaker M, Swann K: Sperm-egg fusion is the prelude to the initial $\mathrm{Ca}^{2+}$ increase at fertilization in the mouse. Development 1997, 124 (1):233-241.

113. Manandhar G, Toshimori K: Fate of postacrosomal perinuclear theca recognized by monoclonal antibody MN13 after sperm head microinjection and its role in oocyte activation in mice. Biol Reprod 2003, 68(2):655-663.

114. Sutovsky P, Manandhar G, Wu A, Oko R: Interactions of sperm perinuclear theca with the oocyte: Implications for oocyte activation, antipolyspermy defense, and assisted reproduction. Microsc Res Tech 2003, 61 (4):362-378.

115. Aghajanpour S, Ghaedi K, Salamian A, Deemeh MR, Tavalaee M, Moshtaghian J, Parrington J, Nasr-Esfahani MH: Quantitative expression of phospholipase $C$ zeta, as an index to assess fertilization potential of a semen sample. Hum Reprod 2011, 26(11):2950-2956.

116. Jin M, Fujiwara E, Kakiuchi Y, Okabe M, Satouh Y, Baba SA, Chiba K, Hirohashi N: Most fertilizing mouse spermatozoa begin their acrosome reaction before contact with the zona pellucida during in-vitro fertilization. Proc Natl Acad Sci 2011, 108(12):4892-4896.

117. Aarabi M, Yu Y, Xu W, Tse MY, Pang SC, Yi Y-J, Sutovsky P, Oko R: The testicular and epididymal expression profile of $P L C \zeta$ in mouse and human does not support its role as a sperm-borne oocyte activating factor. PLOS ONE 2012, 7(3):e33496.

118. Heytens E, Schmitt-John T, Moser JM, Jensen NM, Soleimani R, Young C, Coward K, Parrington J, De Sutter P: Reduced fertilization after ICSI and abnormal phospholipase $C$ zeta presence in spermatozoa from the wobbler mouse. Reprod Biomed Online 2010, 21(6):742-749.

119. Gur Y, Breitbart H: Mammalian sperm translate nuclear-encoded proteins by mitochondrial-type ribosomes. Genes Dev 2006, 20(4):411-416.

120. Boerke A, Dieleman SJ, Gadella BM: A possible role for sperm RNA in early embryo development. Theriogenology 2007, 68:S147-S155. Supplement 1(0.

121. Lalancette C, Miller D, Li Y, Krawetz SA: Paternal contributions: New functional insights for spermatozoal RNA. J Cell Biochem 2008, 104 (5):1570-1579.

122. Garrido N, Martinez-Conejero JA, Jauregui J, Horcajadas JA, Simon C, Remohi J, Meseguer M: Microarray analysis in sperm from fertile and infertile men without basic sperm analysis abnormalities reveals a significantly different transcriptome. Fertil Steril 2009, 91(4, Supplement):1307-1310.

123. Sousa M, Tesarik J: Fertiliza1tion and early embryology: Ultrastructural analysis of fertilization failure after intracytoplasmic sperm injection. Hum Reprod 1994, 9(12):2374-2380.

124. Mahutte NG, Arici A: Failed fertilization: is it predictable? Curr Opin Obstet Gynecol 2003, 15(3):211-218.

125. Swann K, Larman MG, Saunders CM, Lai FA: The cytosolic sperm factor that triggers $\mathrm{Ca}^{2+}$ oscillations and egg activation in mammals is a novel phospholipase C: PLCC. Reproduction 2004, 127(4):431-439.

126. Swain JE, Pool TB: ART failure: oocyte contributions to unsuccessful fertilization. Hum Reprod Update 2008, 14(5):431-446.

127. Mehlmann LM, Kline D: Regulation of intracellular calcium in the mouse egg: calcium release in response to sperm or inositol trisphosphate is enhanced after meiotic maturation. Biol Reprod 1994, 51(6):1088-1098.

128. Xu Z, Kopf GS, Schultz RM: Involvement of inositol 1,4,5-trisphosphatemediated $\mathrm{Ca}^{2+}$ release in early and late events of mouse egg activation. Development 1994, 120(7):1851-1859.

129. Wakai T, Vanderheyden V, Fissore $\mathrm{RA} \mathrm{Ca}^{2+}$ signaling during mammalian fertilization: requirements, players, and adaptations. Cold Spring Harb Perspect Biol 2011, 3(4):pii: a006767.

130. Ducibella T, Dubey A, Gross V, Emmi A, Penzias AS, Layman L, Reindollar R: A zona biochemical change and spontaneous cortical granule loss in eggs that fail to fertilize in in-vitro fertilization. Fertil Steril 1995, 64 (6):1154-1161

131. Verza SJ, Esteves SC: Sperm defect severity rather than sperm source is associated with lower fertilization rates after intracytoplasmic sperm injection. Int Braz J Urol 2008, 34(1):49-56.

132. Kashir J, Konstantinidis M, Jones C, Lemmon B, Chang Lee $H$, Hamer R, Heindryckx B, Deane CM, de Sutter P, Fissore RA, Parrington J, Wells D, Coward K: A maternally inherited autosomal point mutation in human phospholipase C zeta (PLC) leads to male infertility. Hum Reprod 2012, 27(1):222-231.

133. Taylor SL, Yoon SY, Morshedi MS, Lacey DR, Jellerette T, Fissore RA Oehninger S: Complete globozoospermia associated with PLC deficiency treated with calcium ionophore and ICSI results in pregnancy. Reprod Biomed Online 2010, 20(4):559-564.

134. Heindryckx B, Van der Elst J, De Sutter P, Dhont M: Treatment option for sperm- or oocyte-related fertilization failure: assisted oocyte activation following diagnostic heterologous ICSI. Hum Reprod 2005, 20(8):2237-2241

135. Flaherty SP, Payne D, Matthews CD: Fertilization failures and abnormal fertilization after intracytoplasmic sperm injection. Hum Reprod 1998, 13 (suppl 1):155-164.

136. Heindryckx B, Gheselle SD, Gerris J, Dhont M, De Sutter P: Efficiency of assisted oocyte activation as a solution for failed intracytoplasmic sperm injection. Reprod Biomed Online 2008, 17(5):662-668.

137. Eldar-Geva T, Brooks B, Margalioth EJ, Zylber-Haran E, Gal M, Silber SJ: Successful pregnancy and delivery after calcium ionophore oocyte activation in a normozoospermic patient with previous repeated failed fertilization after intracytoplasmic sperm injection. Fertil Steril 2003, 79:1656-1658

138. Ozil JP: The parthenogenetic development of rabbit oocytes after repetitive pulsatile electrical stimulation. Development 1990, 109 (1):117-127

139. Ciapa B, Arnoult C: Could modifications of signalling pathways activated after ICSI induce a potential risk of epigenetic defects? Int J Dev Biol 2011, 55:143-152.

140. Avendano C, Oehninger S: DNA Fragmentation in Morphologically Normal Spermatozoa: How Much Should We Be Concerned in the ICSI Era? J Androl 2011, 32(4):356-363.

141. Kishikawa H, Wakayama T, Yanagimachi R: Comparison of oocyte-activating agents for mouse cloning. Cloning 1999, 1(3):153-159.

142. Fissore RA, Pinto-Correia C, Robl JM: Inositol trisphosphate-induced calcium release in the generation of calcium oscillations in bovine eggs. Biol Reprod 1995, 53(4):766-774.

143. Alberio R, Zakhartchenko V, Motlik J, Wolf E: Mammalian oocyte activation: lessons from the sperm and implications for nuclear transfer. Int J Dev Biol 2001, 45(7):797-809.

144. Zhang D, Pan L, Yang L-H, He X-K, Huang X-Y, Sun F-Z: Strontium promotes calcium oscillations in mouse meiotic oocytes and early embryos through $\operatorname{Ins} \mathrm{P}_{3}$ receptors, and requires activation of phospholipase and the synergistic action of $\operatorname{InsP}_{3}$. Hum Reprod 2005, 20 (11):3053-3061.

145. Chen J, Qian Y, Tan Y, Mima H: Successful pregnancy following oocyte activation by strontium in normozoospermic patients of unexplained infertility with fertilisation failures during previous intracytoplasmic sperm injection treatment. Reprod Fertil Dev 2010, 22(5):852-855.

146. Spadafora C: Endogenous reverse transcriptase: a mediator of cell proliferation and differentiation. Cytogenet Genome Res 2004, 105 (2-4):346-350.

147. Cooper TG, Noonan E, von Eckardstein S, Auger J, Baker HWG, Behre HM, Haugen TB, Kruger T, Wang C, Mbizvo MT, Vogelsong KM: World Health Organisation reference values for human semen characteristics. Hum Reprod Update 2010, 16(3):231-245.

148. Garrido N, Meseguer M, Alvarez J, Simon C, Pellicer A, Remohi J: Relationship among standard semen parameters, glutathione peroxidase/glutathione reductase activity, and mRNA expression and reduced glutathione content in ejaculated spermatozoa from fertile and infertile men. Fertil Steril 2004, 82:1059-1066. Supplement 3(0).

149. Lukanov TH, Lichev DI, Konova El, Emin Al, Ayvazova NP, Velkova AV, Roussev RG: Flow cytometric measurement of sperm nuclear DNA fragmentation in infertile men with normal standard sperm parameters. J Mens Health 2009, 6(1):50-55.

150. Tavalaee M, Kiani A, Arbabian M, Deemeh MR, Nasr-Esfahani MH: Flow Cytometry: A New Approach for Indirect Assessment of Sperm Protamine Deficiency. Int J Fertil Steril 2010, 3(4):177-184.

151. Zribi N, Feki Chakroun N, ElEuch H, Gargouri J, Bahloul A, Ammar Keskes L: Effects of cryopreservation on human sperm deoxyribonucleic acid integrity. Fertil Steril 2010, 93(1):159-166.

152. Kashir J, Heynen A, Jones C, Durrans C, Craig J, Gadea J, Turner K, Parrington J, Coward K: Effects of cryopreservation and density-gradient washing on 
phospholipase $\mathrm{C}$ zeta concentrations in human spermatozoa. Reprod Biomed Online 2011, 23(2):263-267.

153. Meseguer M, de los Santos MJ, Simon C, Pellicer A, Remohi J, Garrido N: Effect of sperm glutathione peroxidases 1 and 4 on embryo asymmetry and blastocyst quality in oocyte donation cycles. Fertil Steril 2006, 86 (5):1376-1385.

154. Krawetz SA, Kramer JA, McCarrey JR: Reprogramming the male gamete genome: a window to successful gene therapy. Gene 1999, 234(1):1-9.

155. Krawetz SA: Paternal contribution: new insights and future challenges. Nat Rev Genet 2005, 6(8):633-642.

156. Ostermeier GC, Goodrich RJ, Diamond MP, Dix DJ, Krawetz SA: Toward using stable spermatozoal RNAs for prognostic assessment of male factor fertility. Fertil Steril 2005, 83(6):1687-1694.

157. Miller D, Ostermeier GC, Krawetz SA: The controversy, potential and roles of spermatozoal RNA. Trends Mol Med 2005, 11(4):156-163.

158. Miller D, Ostermeier GC: Towards a better understanding of RNA carriage by ejaculate spermatozoa. Hum Reprod Update 2006, 12(6):757-767.

159. Ajduk A, llozue T, Windsor S, Yu Y, Seres KB, Bomphrey RJ, Tom BD, Swann K, Thomas A, Graham C, Zernicka-Goetz M: Rhythmic actomyosin-driven contractions induced by sperm entry predict mammalian embryo viability. Nat Commun 2011, 2:417-426.

160. Swann K, Windsor S, Campbell K, Elgmati K, Nomikos M, Zernicka-Goetz M, Amso N, Lai FA, Thomas A, Graham C: Phospholipase C- $\zeta$-induced Ca ${ }^{2+}$ oscillations cause coincident cytoplasmic movements in human oocytes that failed to fertilize after intracytoplasmic sperm injection. Fertil Steril 2012, 97(3):742-747.

161. Zhang N, Wakai T, Fissore RA: Caffeine alleviates the deterioration of $\mathrm{Ca}^{2+}$ release mechanisms and fragmentation of in-vitro-aged mouse eggs. Mol Reprod Dev 2011, 78(9):684-701.

162. Wu TF, Chu DS: Sperm Chromatin. Mol Cell Proteomics 2008, 7(10):1876-1886.

doi:10.1186/1478-811X-10-12

Cite this article as: Ramadan et al:: Oocyte activation and phospholipase C zeta (PLCC): diagnostic and therapeutic implications for assisted reproductive technology. Cell Communication and Signaling 2012 10:12.

\section{Submit your next manuscript to BioMed Central and take full advantage of:}

- Convenient online submission

- Thorough peer review

- No space constraints or color figure charges

- Immediate publication on acceptance

- Inclusion in PubMed, CAS, Scopus and Google Scholar

- Research which is freely available for redistribution 